\title{
DIGITAL SOLUTION OF THE REACTOR KINETIC EQUATIONS BY THE THETA METHOD FOR FAST (FFTF) AND THERMAL REACTORS
}

February 1969

\section{AEC RESEARCH \& DEVELOPMENT REPORT}

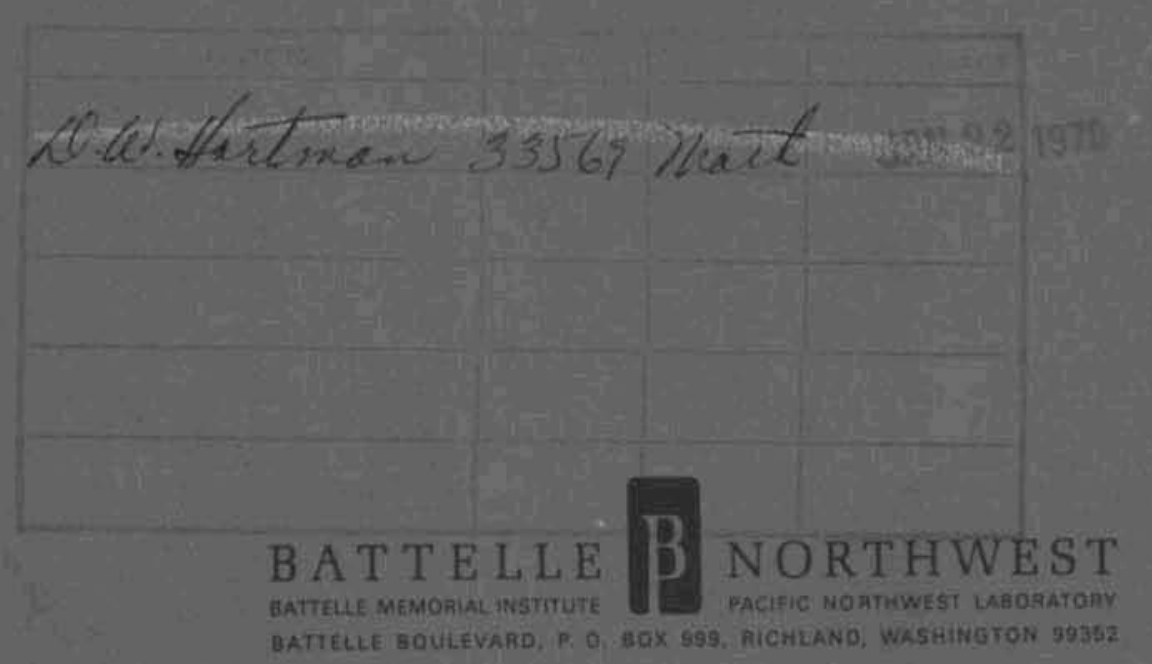




\section{LEGAL NOTICE}

This report was prepared as an account of Government sponsored work. Neittier the United States, nor the Commission, nor any person acting on behalf of the Commission:

A. Makes any watronty of representation, expressed on implied, with reapect to the occuracy, com. pleteness; or usefulness of the information contained in this report, or that the use of any information, opparatus, method, or process disclosed in this report may not infringe privately owned rights; or:

B. Assumes any liabilities with respect to the use of, or for damaget rasulting from the use of ony information, appatatus, method, or process disclosed in this report.

As used in the above, "person octing on betialf of the Commission" includes any emplayes or contractor of the Commision, or emplayee of such contractor, to the extent that such employee or con. tractor of the Commission, or employee of such contractor prepares, disseminates, or provides access to, any informotion pursuant to his employment or controct with the Cornmission, or his employment with such controctor:

\section{PACIFIC NORTHWEST LABORATORY RICHLAND, WASHINGTON \\ operated by} BATTELLE MEMORIAL INSTITUTE

for the

UNITED STATES ATOMIC ENERGY COMMISSION UNDER CONTRACT AT(45-1)-1830 


\title{
33679000612046
}

BNWL -940

UC-32, Mathematics and Computers

\author{
DIGITAL SOLUTION \\ OF THE REACTOR KINETIC EQUATIONS \\ BY THE THETA METHOD \\ FOR FAST (FFTF) \\ AND THERMAL REACTORS \\ By \\ R. A. Burnett \\ Control and Instrumentation Department \\ Systems and Electronics Division \\ $f$. \\ DISTA \\ 19 \\ February 1969
}

BATTELLE MEMORIAL INSTITUTE

PACIFIC NORTHWEST LABORATORY

RICHLAND, WASHINGTON 99352 
Printed in the United States of America Available from

Clearinghouse for Federal Scientific and Technical Information National Bureau of Standards, U.S. Department of Commerce Springfield, Virginia 22151

Price: Printed Copy $\$ 3.00$; Microfiche $\$ 0.65$ 


\title{
DIGITAL SOLUTION \\ OF THE REACTOR KINETIC EQUATIONS \\ BY THE THETA METHOD \\ FOR FAST (FFTF) \\ AND THERMAL REACTORS
}

R. A. Burnett

\begin{abstract}
Three variations of a digital integration formula known as the Theta method were used to solve the nuclear reactor point kinetics equations on a Digital Equipment Corporation PDP-7 computer. The equations were also solved by trapezoidal integration. A three-delay-group model was programmed with thermal reactor parameters. Printout solutions were obtained for a reactivity step input of -0.005 and were compared to an analytical solution. For other reactivity inputs, hybrid equipment was used to compare the digital results to an analog solution computed simultaneously on a Beckman EASE 2133 analog computer. The analytical and analog solutions were assumed to be the "true" solutions. Fast reactor constants were then inserted and the tests repeated. A simple modification of one of the weighting parameters displayed a definite accuracy advantage over integration by the trapezoidal rule in the calculation of fast transients, although it required nearly two and one-half times the solution time of the trapezoidal method. In the case of more slowly changing power levels, the trapezoidal rule was able to nearly match the accuracy of the Theta method. A simplified variation of the Theta method required on 1 y 20 to $35 \%$ more solution time than trapezoidal integration while handling fast transients nearly as well as the more complex Theta variation. With the fast reactor mode1, the Theta and trapezoidal methods produced nearly identical results; both had good accuracy.
\end{abstract}




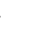


TABLE OF CONTENTS

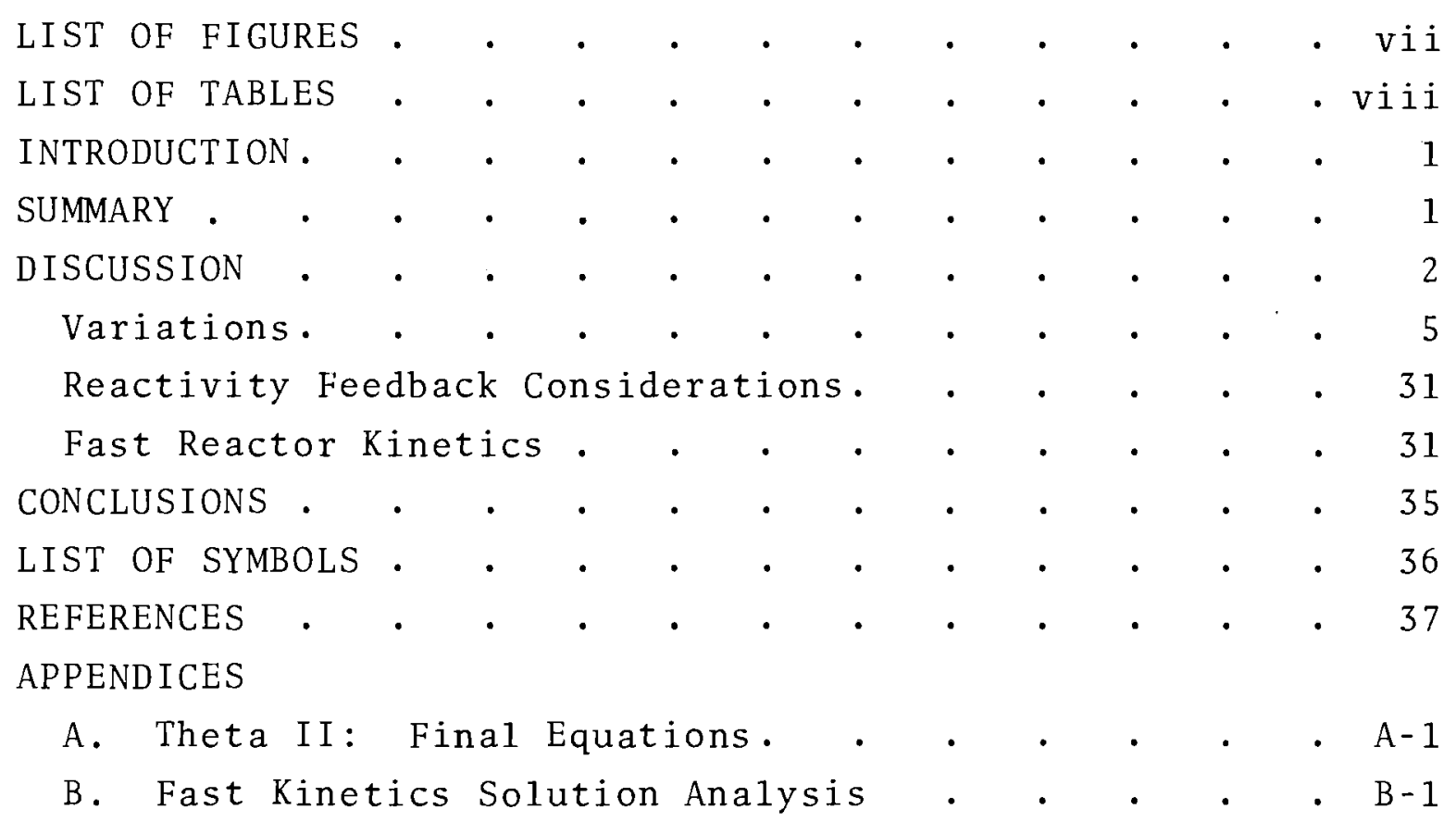




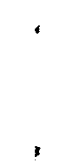

$?$ 


\section{LIST OF FIGURES}

1 Solution Timing for Step Inputs

2a Normalized Thermal Reactor Response to a Reactivity Step Change of -0.005 Occurring at $t=0.05$

2b Error Signals Expressed as a Fraction of Initial Neutron Level

3 a Normalized Thermal Reactor Response to a Reactivity Step Change of -0.005 Occurring at $t=0.20$

3b Error Signals

4 a Normalized Thermal Reactor Response to a Reactivity Step Change of -0.005 Occurring at $t=0.40$

4 b Error Signals

5 a Normalized Thermal Reactor Response to a Reactivity Step Change of -0.020 Occurring at $t=0.05$

$5 b \quad$ Error Signals

6 a Normalized Thermal Reactor Response to a Reactivity Step Change of -0.020 Occurring at $t=0.20$

6b Error Signals

7a Normalized Thermal Reactor Response to a Reactivity Step Change of +0.003 Occurring at $t=0.05$

$7 \mathrm{~b} \quad$ Error Signals

8 a Normalized Thermal Reactor Response to a Reactivity Ramp Input of $+0.001 t$ Occurring at $t=0$

8b Error Signals for Figure $8 \mathrm{a}$

9 a Normalized Thermal Reactor Response to a Reactivity Ramp Input of $-0.003 t$ Occurring at $t=0$

9b Error Signals for Figure 9a

10a Normalized Thermal Reactor Response to a Reactivity Step Change of -0.005 Occurring at $t=0.05$, with Doppler Feedback 


\section{LIST OF TABLES}

1 Thermal Reactor Response to a Reactivity Step Change of -0.005 Occurring at $t=0.05$ :

Theta Method Test Number 1

2 Thermal Reactor Response to a Reactivity Step Change of -0.005 Occurring at $t=0.05$ :

Theta Method Test Number 2

PDP- 7 Solution Times for Theta Methods and

Trapezoidal Rule: Three-Delay-Group Thermal

Reactor Kinetics

4 Thermal Reactor Response to a Reactivity Step Change of -0.005 Occurring at $t=0.025$;

Theta Selective

5 Fast Reactor Response to a Reactivity Step Change of -0.005 Occurring at $t=0.05:$ Thet a Method Test Number 3

6 Fast Reactor Response to a Reactivity Step Change of -0.005 Occurring at $t=0.20$ : Theta Method

Test Number 3 


\section{DIGITAL SOLUTION \\ OF THE REACTOR KINETIC EQUATIONS \\ BY THE THETA METHOD \\ FOR FAST (FFTF) \\ AND THERMAL REACTORS}

R. A. Burnett

\section{INTRODUCTION}

Three variations of a digital integration formula known as the Theta method were used to solve the nuclear reactor point kinetics equations on a Digital Equipment Corporation PDP-7 computer. The equations were also solved by trapezoidal integration. The purpose of this study was to determine the relative accuracy and efficiency of each method in real-time simulation.

A three-delay-group mode1 was programmed with thermal reactor parameters. Printout solutions were obtained for a reactivity step input of -0.005 and were compared to an analytical solution. For other reactivity inputs, hybrid equipment was used to compare the digital results to an analog solution computed simultaneously on a Beckman EASE 2133 analog computer. The analytical and analog solutions were assumed to be the "true" solutions. Fast reactor constants were then inserted and the tests repeated.

\section{SUMMARY}

A simple modification of one of the weighting parameters resulted in an improvement of the basic Theta method. With the thermal reactor model, the improved Theta method displayed a definite accuracy advantage over integration by the trapezoidal rule in the calculation of fast transients, although it required nearly two and one-half times the solution time of the 
trapezoidal method. In the case of more slowly changing power levels, the trapezoidal rule was able to nearly match the accuracy of the Theta method. A simplified variation of the Theta method required only 20 to $35 \%$ more solution time than trapezoidal integration while handling fast transients nearly as wel1 as the more complex Theta variation. With the fast reactor model, the Theta and trapezoidal methods produced nearly identical results; both had good accuracy.

\section{DISCUSSION}

The kinetics equations to be solved are:

$$
\begin{aligned}
& \frac{d N(t)}{d t}=\frac{\rho-\beta}{\ell^{\hbar}} N(t)+\sum_{i=1}^{G} \lambda_{i} C_{i}(t) \\
& \frac{d C_{i}(t)}{d t}=\frac{\beta}{l^{\star}} N(t)-\lambda_{i} C_{i}(t) \quad(i=1,2, \ldots, G)
\end{aligned}
$$

Three-delay-group representations were used in both the thermal reactor and fast reactor models. Except for a brief investigation involving Doppler feedback, the reactivity $\rho$ was determined entirely by a specified input function: i.e., $\rho=\rho(t)$. Step and ramp inputs, both positive and negative, were selected.

The Theta method can be thought of as a modification of closed trapezoidal integration in which the averaging factor of 0.5 , applied to the sum of the past and present values of the derivative, is replaced by one or more variable weighting parameters, $\theta_{i}$, which may take on values between zero and one. The manner in which the values of $\theta_{i}$ are calculated determines the particular variation of the method.

The following variation, applied to the kinetics equations, has been found by others $(1,2,3)$ to be quite successful. It will hereafter be referred to as "Theta I": 


$$
\begin{aligned}
N^{j+1}= & N^{j}+\Delta t \theta_{1}^{j}\left(\frac{\rho^{j+1}-\beta}{\ell^{*}}\right) N^{j+1} \\
& +\Delta t\left(1-\theta \frac{j}{1}\right)\left(\frac{\rho^{j}-\beta}{\ell^{*}}\right) N^{j} \\
& +\sum_{i=1}^{G} \Delta t \lambda_{i}\left[\theta \frac{\theta_{2}^{j}}{C_{i}^{j+1}}+\left(1-\theta \frac{j}{2}\right) C_{i}^{j}\right] \\
C_{i}^{j+1}= & C_{i}^{j}+\Delta t\left(\frac{\beta i}{\ell^{*}}\right)\left[\theta{ }_{1}^{j} N^{j+1}+\left(1-\theta \frac{1}{1}\right) N^{j}\right] \\
& -\Delta t \lambda_{i}\left[\theta_{2}^{j} C_{i}^{j+1}+\left(1-\theta_{2}^{j}\right) C_{i}^{j}\right] \quad(i=1,2, \ldots, G)
\end{aligned}
$$

$$
\theta_{i}= \begin{cases}\frac{1}{\omega_{i} \Delta t}-\frac{1}{\exp \left(\omega_{i} \Delta t\right)-1} & \left|\omega_{i} \Delta t\right|>\quad K \\ \frac{1}{2}-\frac{\omega_{i} \Delta t}{12} & \left|\omega_{i} \Delta t\right| \leq \quad k \\ & (i=1,2)\end{cases}
$$

$$
\omega_{1}^{j}= \begin{cases}\frac{\rho^{j}-\beta}{\ell^{*}} & \rho^{j}<\beta \\ 0 & \rho^{j} \geq \beta\end{cases}
$$




$$
\omega_{2}^{j}= \begin{cases}\frac{\ell^{*}}{\beta-\rho^{j}} \sum_{i=1}^{G} \lambda_{i}\left(\frac{\beta_{i}}{\ell^{*}}-\frac{\lambda_{i} C_{i}^{j}}{N^{j}}\right) & \rho^{j}<0.1 \frac{\left(\beta-\rho^{j}\right)^{2}}{\ell^{*}} \\ \frac{\rho^{j}-\beta}{\ell^{*}}+\sum_{i=1}^{G} \lambda_{i} \frac{C_{i}^{j}}{N^{j}} & \rho^{j} \geq 0.1 \frac{\left(\beta-\rho^{j}\right)^{2}}{\ell^{*}}\end{cases}
$$

The superscripts $j$ and $j+1$ refer to the old and new variable values, respectively. A 1 ist of symbols appears on page 36. The integration step size is $\Delta t$. The PDP-7 was able to provide accurate computation of the $\theta$ function with $K=0.8$. Notice that if $\theta_{1}=\theta_{2}=0.5$, Equations (3) and (4) become identical to those which would result from an application of the trapezoidal rule to Equations (1) and (2).

Equation (4) can be solved for $\mathrm{C}_{i}^{j+1}$ and substituted into Equation (3) to obtain:

$$
\begin{aligned}
& N^{j+1}=f_{o}\left(N^{j}, C_{1}^{j}, C_{2}^{j}, \ldots, C_{G}^{j}, \rho j+1, \rho\right) \\
& C_{i}^{j+1}=f_{i}\left(N^{j+1}, N^{j}, C_{i}^{j}\right) \\
& (i=1,2, \ldots, G)
\end{aligned}
$$

If this method is to be used in a real-time simulation, it is important that the frame time (time required by the computer to calculate a new set of variable values) be as small as possible while maintaining accurate solutions. It was therefore important to know the accuracy and frame time of Theta $I$ and to investigate the possibility of altering this method to reduce the frame time without significantly impairing the accuracy. 
It should be noted here that the Theta method, like the trapezoidal rule, is an implicit form of integration and therefore cannot predict a new solution ahead of the instant of time at which that solution is valid, unless the reactivity input is known ahead of time. If the reactivity input is an analog signal, the computer must monitor that input at time $t^{j+1}$ before it can complete the calculation of $\mathrm{N}^{j^{+1}}$ and $\mathrm{c}_{i}^{j^{+1}}$. The updating of the complete solution will thus experience a time delay equal to the frame time. If $\mathrm{N}^{\mathrm{j}^{+1}}$ is the on 1 y varible of interest to the remainder of the simulation system, then the delay will be somewhat less than the total frame time.

VARI ATIONS

It is evident that a value for $\theta_{1}$ at time $t_{j+1}$ could be calculated, using Equation (5) with

$$
\omega_{1}^{j+1}= \begin{cases}\frac{\rho^{j+1}-\beta}{\ell^{*}} & \rho^{j+1}<\beta \\ 0 & \rho^{j+1} \geq \beta\end{cases}
$$

It would thus seem logical and beneficial to replace $\theta_{1}^{j}$ with $\theta_{1}^{j+1}$ in those terms in Equations (3) and (4) which multiply $(j+1)$ variables by $\theta_{1}$. This can be done with no increase in frame time. A corresponding change cannot be made with $\theta_{2}^{j+1}$ because of its dependency upon quantities which are not yet available $\left(N^{j+1}, C_{i}^{j+1}\right)$. Equations (3) and (4) now become: 


$$
\begin{aligned}
N^{j+1}= & N^{j}+\Delta t \theta_{1}^{j+1}\left(\frac{\rho^{j+1}-\beta}{\ell^{*}}\right) N^{j+1} \\
& +\Delta t\left(1-\theta \frac{\rho^{j}-\beta}{\ell^{*}}\right] N^{j} \\
& +\sum_{i=1}^{G} \Delta t \lambda_{i}\left[\theta{ }_{2}^{j} C_{i}^{j+1}+\left(1-\theta \frac{2}{2}\right) C_{i}^{j}\right] \\
C_{i}^{j+1}= & C_{i}^{j}+\Delta t\left(\frac{\beta}{\ell^{*}}\right)\left[\theta_{1}^{j+1} N^{j+1}+\left(1-\theta{ }_{1}^{j}\right) N^{j}\right] \\
& -\Delta t \lambda_{i}\left[\theta_{2}^{j} C_{i}^{j+1}+\left(1-\theta \frac{1}{2}\right) C_{i}^{j}\right](i=1,2, \ldots, G)
\end{aligned}
$$

Equations (5), (6), and (7), with the addition of Equation (10), still apply. This variation will be called Theta II. The final form of Equations (11) and (12), rearranged according to the manner of Equations (8) and (9), is 1 isted in Appendix A.

As a trial problem, the point kinetics equations were programmed using typical three-delay-group thermal reactor parameters. Provision was made such that Theta I, Theta II, or trapezoidal integration could be selected. The analytical solution to the problem of a step reactivity input of -0.005 was derived, using Laplace transforms, as a reference solution. The digital solutions were started from a steady-state condition with zero reactivity at $t_{0}=0$, and the reactivity was stepped to its full value at the first iteration $\left(t_{1}=\Delta t\right)$. If an analog reactivity signal were being monitored, the exact time at which the reactivity changed could have been anywhere from just after $t_{0}$ to just before $t_{1}$. The average of the possibilities would be at $t=\left(t_{0}+t_{1}\right) / 2=\Delta t / 2$. It would seem likely, then, that the digital solutions should most nearly match the true solution to a reactivity step occurring at $t=\Delta t / 2$. For this reason, comparison was made with the analytical solution stepped at $t=\Delta t / 2$. 
Table 1 shows the $N(t)$ solutions from zero to $3.5 \mathrm{sec}$ with a time step of 0.1 sec. Let us examine their relative accuracies in two phases: the accuracy of the first few points of the transient, and the amount of error that has accumulated after 2 to 3 sec.

The Theta II variation was greatly superior in the calculation of the first two points of the transient, with Theta I running second and the trapezoidal rule coming in last. At $0.2 \mathrm{sec}$, the percent errors were $4.28,0.93$, and $0.12 \%$ for trapezoidal, Theta I, and Theta II, respectively. After five iterations, the Theta I solution converged to the same value as the Theta II solution and remained there to the termination of the test. The trapezoidal solution continued to be farthest from the analytical solution and was drifting from that solution at a slightly greater rate than the Theta solutions at the conclusion of the test.

Other reactivity inputs were applied, including step functions ranging from -0.020 to +0.003 and ramp functions ranging from $-0.003 t$ to $+0.0015 t$, and the solutions were compared to points obtained from analog computer strip-chart solutions. The analog solutions to step inputs were started at $t=\Delta t / 2$; solutions to $\mathrm{ramp}$ inputs were started at $t=0$. The results were similar to those of Table 1 with moderate to large reactivity step changes. Theta II was able to follow reactivity ramps more closely than the other two methods. If the reactivity function was a slowly. changing ramp or a small step, the differences in accuracy between the three methods nearly vanished. Increasing the integration step size generally had the expected effect of reducing the accuracy of all three digital solutions, but the relative accuracies among methods remained about the same. 
TABLE 1. Thermal Reactor Response to a Reactivity Step Change of -0.005 occurring at $t=0.05:$ Theta Method Test Number 1 .

\begin{tabular}{|c|c|c|c|c|}
\hline $\begin{array}{c}\text { Time, } \\
\text { sec } \\
\end{array}$ & $\begin{array}{l}\text { Trapezoidal } \\
\text { Rule } \\
\end{array}$ & Theta I & Theta II & $\begin{array}{l}\text { Analytical } \\
\text { Solution }\end{array}$ \\
\hline $\mathrm{T}$ & $10 \mathrm{~N}$ & $10 \mathrm{~N}$ & $10 \mathrm{~N}$ & $10 \mathrm{~N}$ \\
\hline 0.00 & 400.00 & 400.00 & 400.00 & 400.00 \\
\hline 0.10 & 305.92 & 298.34 & 280.79 & 281.84 \\
\hline 0.20 & 209.81 & 221.24 & 218.93 & 219.20 \\
\hline 0.30 & 205.55 & 207.27 & 206.95 & 207.05 \\
\hline 0.40 & 201.35 & 201.87 & 201.82 & 201.92 \\
\hline 0.50 & 197.52 & 197.74 & 197.74 & 197.84 \\
\hline 0.60 & 193.76 & 194.01 & 194.01 & \\
\hline 0.70 & 190.05 & 190.37 & 190.37 & \\
\hline 0.80 & 186.66 & 186.99 & 186.99 & 187.01 \\
\hline 0.90 & 183.33 & 183.68 & 183.68 & \\
\hline 1.00 & 180.17 & 180.47 & 180.47 & \\
\hline 1.10 & 177.15 & 177.42 & 177.42 & 177.50 \\
\hline 1.20 & 174.19 & 174.53 & 174.53 & \\
\hline 1.30 & 171.47 & 171.74 & 171.74 & 171.79 \\
\hline 1.40 & 168.70 & 169.07 & 169.07 & \\
\hline 1.50 & 166.16 & 166.44 & 166.44 & \\
\hline 1.60 & 163.63 & 164.04 & 164.04 & \\
\hline 1.70 & 161.29 & 161.64 & 161.64 & \\
\hline 1.80 & 159.01 & 159.39 & 159.39 & 159.43 \\
\hline 1.90 & 156.73 & 157.14 & 157.14 & \\
\hline 2.00 & 154.63 & 154.99 & 154.99 & \\
\hline 2.10 & 152.59 & 152.97 & 152.97 & \\
\hline 2.20 & 150.67 & 151.09 & 151.09 & \\
\hline 2.30 & 148.88 & 149.22 & 149.22 & 149.34 \\
\hline 2.40 & 146.97 & 147.40 & 147.40 & \\
\hline 2.50 & 145.30 & 145.69 & 145.69 & \\
\hline 2.60 & 143.64 & 143.97 & 143.97 & \\
\hline 2.70 & 141.97 & 142.42 & 142.42 & \\
\hline 2.80 & 140.49 & 140.93 & 140.93 & 141.05 \\
\hline 2.90 & 139.00 & 139.43 & 139.43 & \\
\hline 3.00 & 137.65 & 138.04 & 138.04 & \\
\hline 3.10 & 136.23 & 136.60 & 136.60 & 136.79 \\
\hline 3.20 & 134.81 & 135.25 & 135.25 & \\
\hline 3.30 & 133.63 & 133.97 & 133.97 & \\
\hline 3.40 & 132.40 & 132.74 & 132.74 & \\
\hline 3.50 & 131.16 & 131.57 & 131.57 & 131.79 \\
\hline
\end{tabular}

Another Theta variation resulted from a simplification of Theta II. It was observed that a significant reduction in frame time could be achieved if $\theta_{2}^{j}$ could be approximated by a 
constant. A logical choice for this constant would be 0.5 . Since $\theta_{2}^{j}$ is associated with the slowly changing precursor groups, Theta I n normally calculates $\theta{ }_{2}^{j}$ values which are very close to 0.5 , so this approximation should be a good one. This variation, identical to Theta II except for the restriction of $\theta_{2}^{j}=0.5$, will be called Theta III.

Table 2 lists the trapezoidal, Theta II, and Theta III solutions to the same problem solved in Table 1. Notice that the first few points of the transient are identical in the Theta II and Theta III solutions. Then Theta III begins to drift further from the "true" solution than does Theta II. At 3.5 sec the Theta III solution is only slightly more accurate than the trapezoidal solution $(0.42 \%$ error for Theta II versus 0.48 and $0.17 \%$ for trapezoidal and Theta II, respectively). Other reactivity inputs and time step sizes produced similar results. Again, the differences between solutions were slight for small reactivity changes.

Strip-chart displays of the Theta II, Theta III, trapezoidal, and analog computer responses to various reactivity inputs are shown in Figures 1 through 9. An error signa1, the difference between the digital solution and the analog solution, was plotted for each digital method. The large time steps were used primarily to amplify the error differences in the various methods. Smaller time steps would result in smoother solutions. In a hybrid simulation where analog signals are dependent upon the continuous result of the digitally calculated power level, a smooth solution would be desirable. An al1-digital simulation, working with discrete points for all variables, would be more concerned with the accuracy of the points than the continuity of the solution and could thus accept larger time steps. In a complete reactor plant simulation, the lower limit on the time step 
TABLE 2. Thermal Reactor Response to a Reactivity Step Change of -0.005 occurring at $t=0.05:$ Theta Method Test Number 2.

\begin{tabular}{|c|c|c|c|c|}
\hline $\begin{array}{c}\text { Time, } \\
\text { sec } \\
\end{array}$ & $\begin{array}{l}\text { Trapezoidal } \\
\text { Rule } \\
\end{array}$ & Theta II & Theta III & $\begin{array}{c}\text { Analytical } \\
\text { Solution } \\
\end{array}$ \\
\hline $\mathrm{T}$ & $10 \mathrm{~N}$ & $10 \mathrm{~N}$ & $10 \mathrm{~N}$ & $10 \mathrm{~N}$ \\
\hline 0.00 & 400.00 & 400.00 & 400.00 & 400.00 \\
\hline 0.10 & 305.92 & 280.79 & 280.79 & 281.84 \\
\hline 0.20 & 209.81 & 218.93 & 218.93 & 219.20 \\
\hline 0.30 & 205.55 & 206.95 & 206.95 & 207.05 \\
\hline 0.40 & 201.35 & 201.82 & 201.87 & 201.92 \\
\hline 0.50 & 197.52 & 197.74 & 197.69 & 197.84 \\
\hline 0.60 & 193.76 & 194.01 & 193.95 & \\
\hline 0.70 & 190.05 & 190.37 & 190.37 & \\
\hline 0.80 & 186.66 & 186.99 & 186.94 & 187.01 \\
\hline 0.90 & 183.33 & 183.68 & 183.57 & \\
\hline 1.00 & 180.17 & 180.47 & 180.41 & \\
\hline 1.10 & 177.15 & 177.42 & 177.36 & 177.50 \\
\hline 1.20 & 174.19 & 174.53 & 174.48 & \\
\hline 1.30 & 171.47 & 171.74 & 171.58 & 171.79 \\
\hline 1.40 & 168.70 & 169.07 & 168.96 & \\
\hline 1.50 & 166.16 & 166.44 & 166.35 & \\
\hline 1.60 & 163.63 & 164.04 & 163.83 & \\
\hline 1.70 & 161.29 & 161.64 & 161.47 & \\
\hline 1.80 & 159.01 & 159.39 & 159.12 & 159.43 \\
\hline 1.90 & 156.73 & 157.14 & 156.92 & \\
\hline 2.00 & 154.63 & 154.99 & 154.78 & \\
\hline 2.10 & 152.59 & 152.97 & 152.81 & \\
\hline 2.20 & 150.67 & 151.09 & 150.82 & \\
\hline 2.30 & 148.88 & 149.22 & 148.90 & 149.34 \\
\hline 2.40 & 146.97 & 147.40 & 147.13 & \\
\hline 2.50 & 145.30 & 145.69 & 145.36 & \\
\hline 2.60 & 143.64 & 143.97 & 143.76 & \\
\hline 2.70 & 141.97 & 142.42 & 142.15 & \\
\hline 2.80 & 140.49 & 140.93 & 140.60 & 141.05 \\
\hline 2.90 & 139.00 & 139.43 & 139.16 & \\
\hline 3.00 & 137.65 & 138.04 & 137.72 & \\
\hline 3.10 & 136.23 & 136.60 & 136.33 & 136.79 \\
\hline 3.20 & 134.81 & 135.25 & 134.94 & \\
\hline 3.30 & 133.63 & 133.97 & 133.64 & \\
\hline 3.40 & 132.40 & 132.74 & 132.42 & \\
\hline 3.50 & 131.16 & 131.57 & 131.24 & 131.79 \\
\hline
\end{tabular}




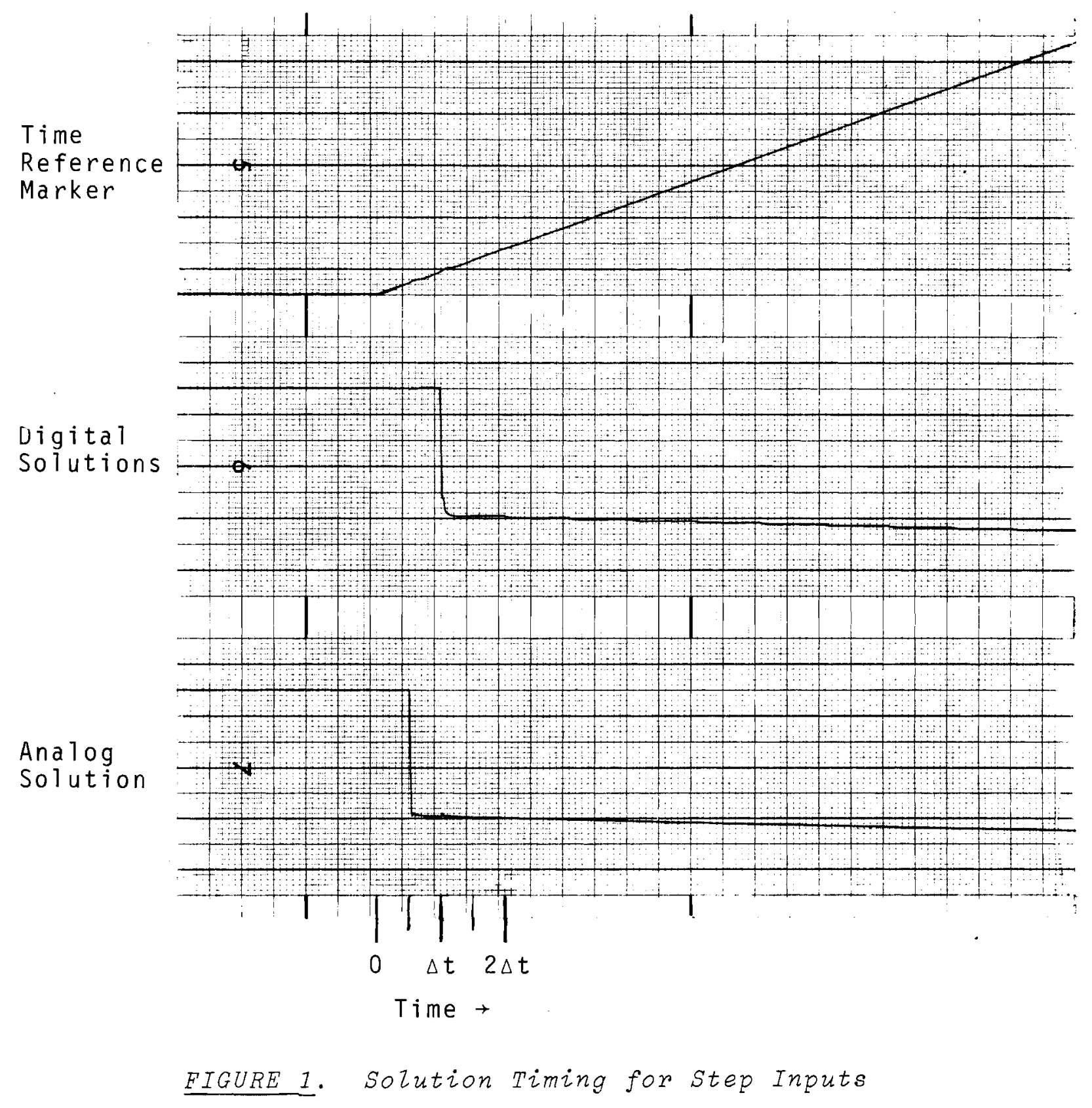




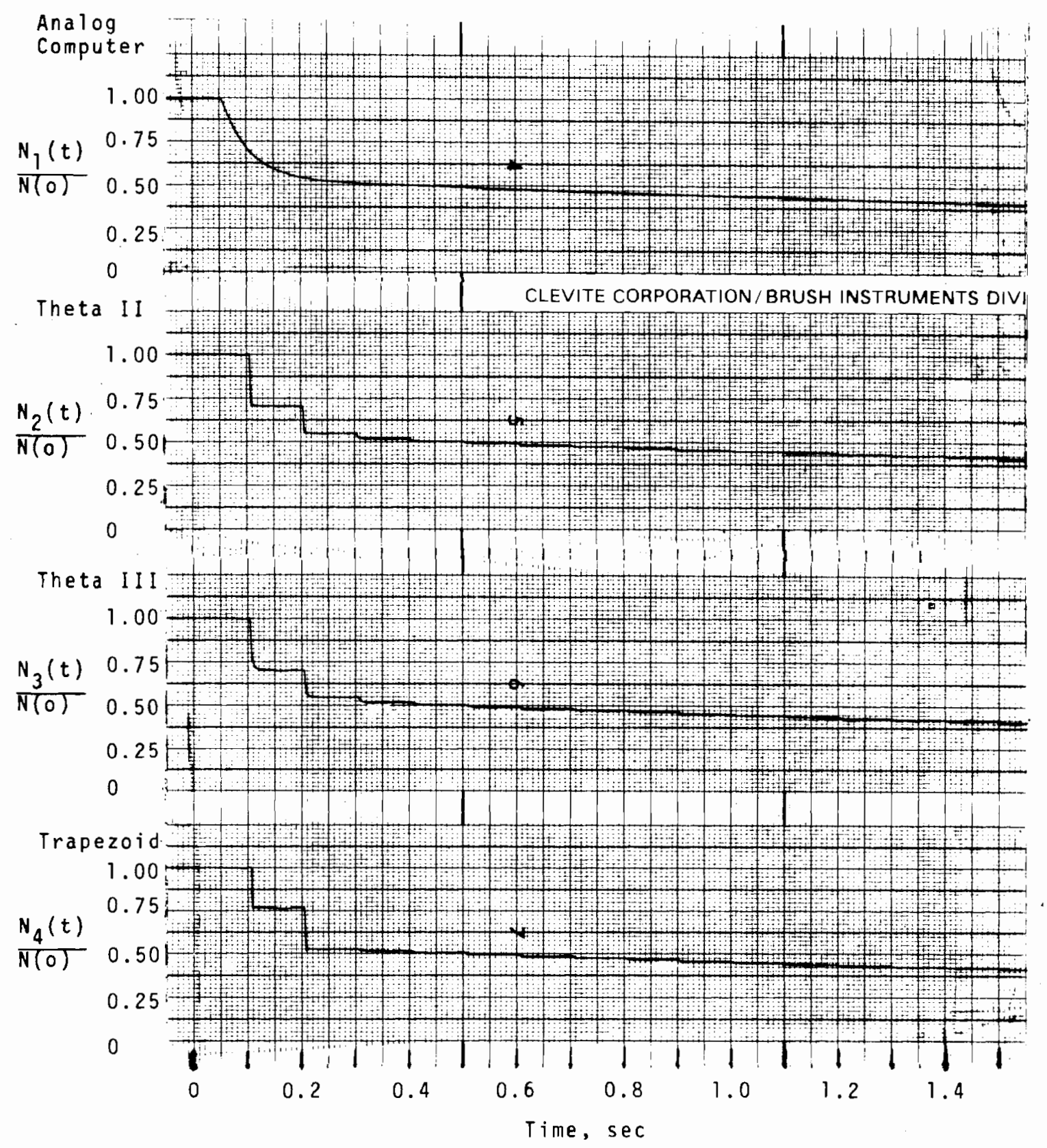

FIGURE 2a. Normalized Thermal Reactor Response to a Reactivity Step Change of -0.005 occurring at $t=0.05$. $\Delta t=0.1 \mathrm{sec}$. 


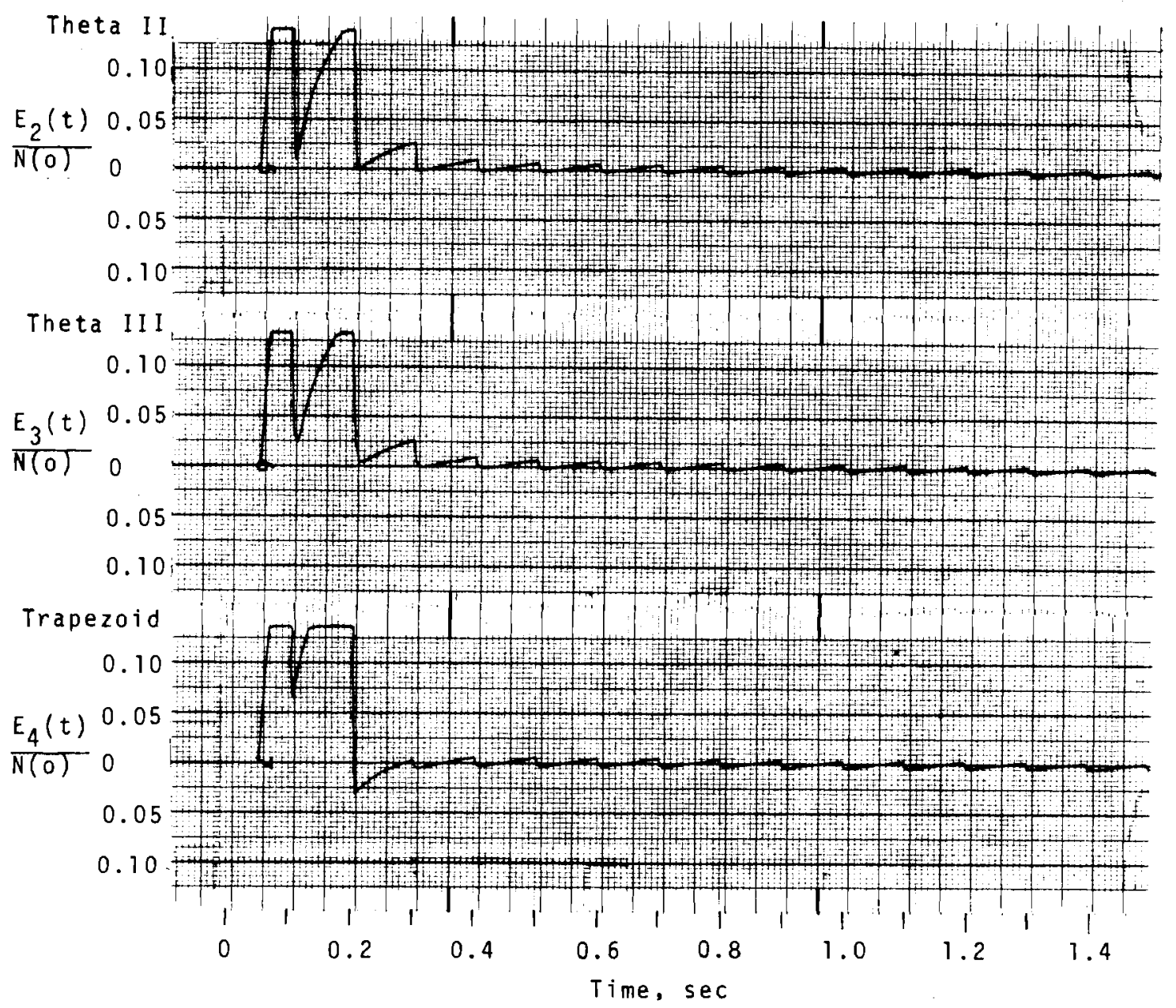

FIGURE 2b. Error Signals Expressed as a Fraction of Initial Neutron Level.

$$
E_{i}(t)=\left|N_{i}(t)-N_{1}(t)\right| \quad(i=2,3,4)
$$




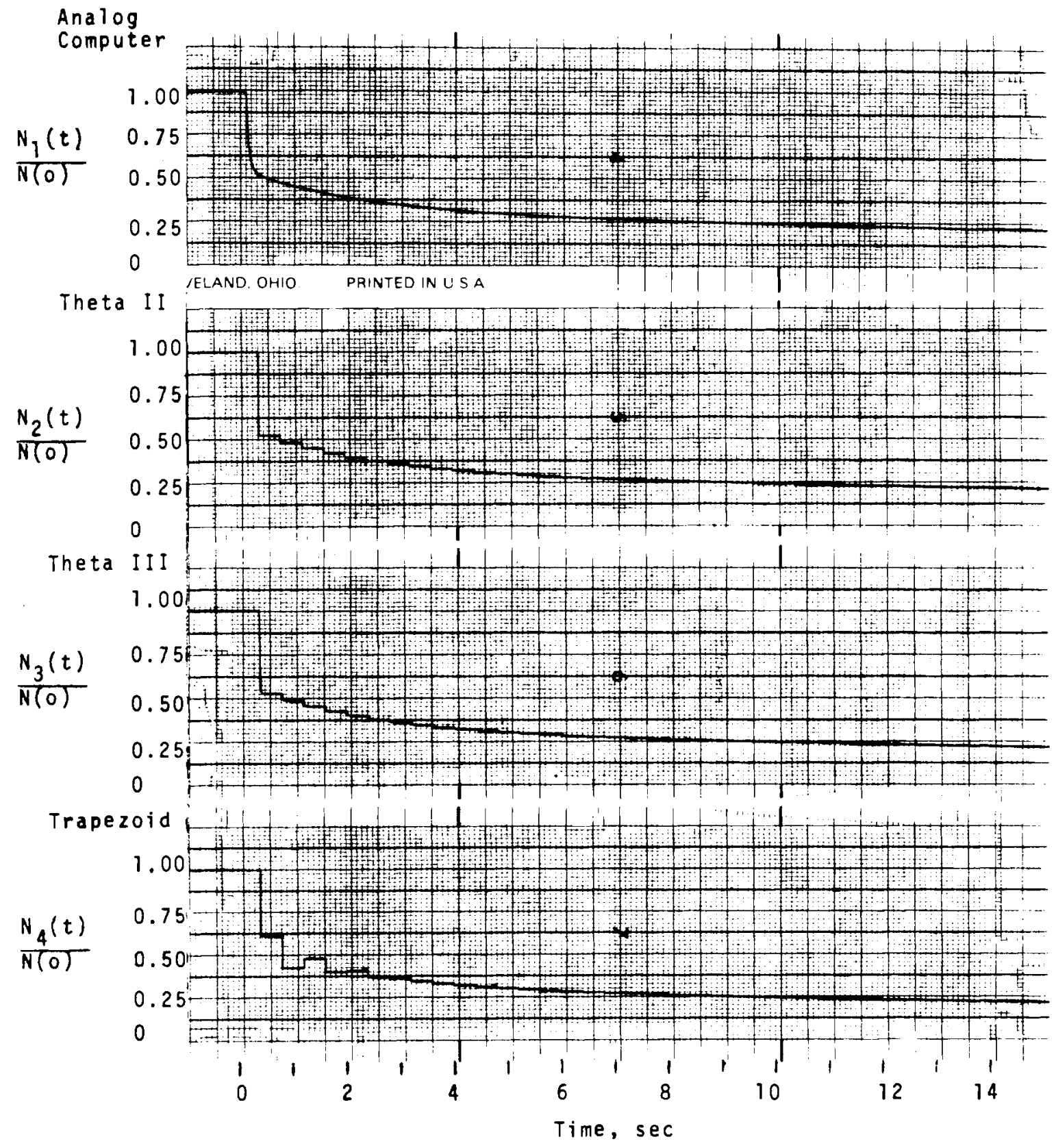

FIGURE 3a. Normalized Thermal Reactor Response to a Reactivity Step Change of -0.005 occurring at $t=0.20$. $\Delta t=0.4 \mathrm{sec}$ 


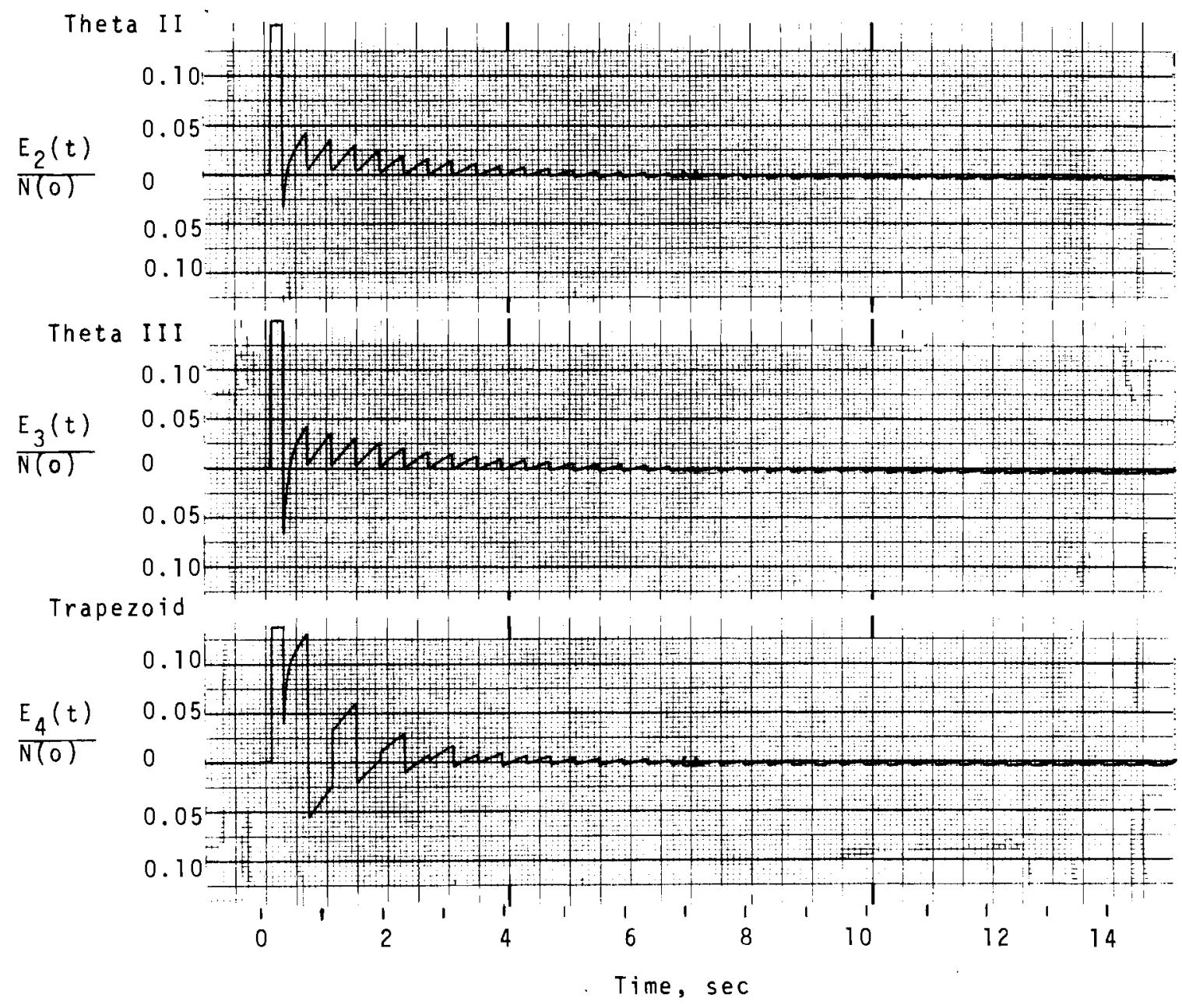

FIGURE 3b. Error Signals 

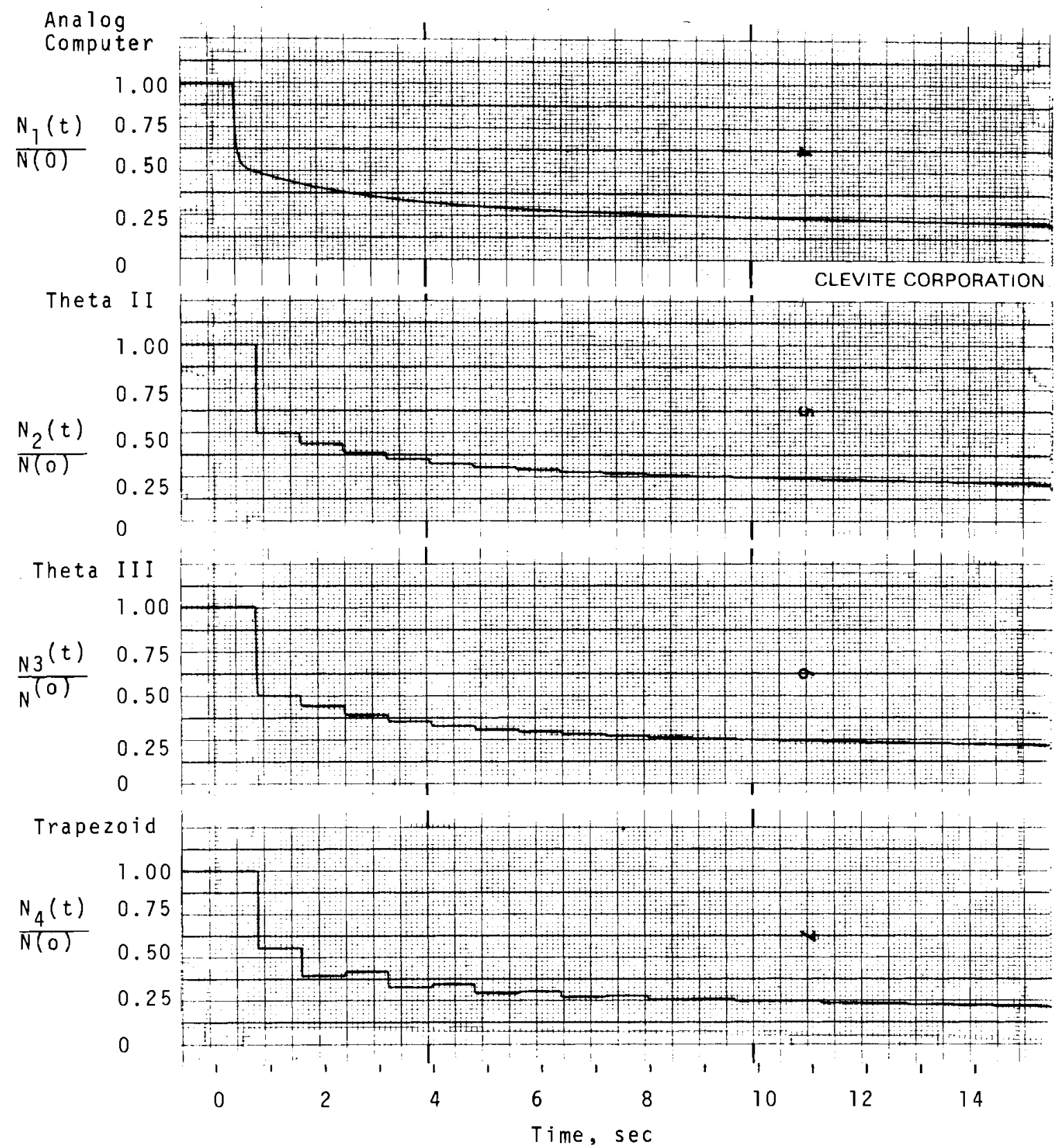

FIGURE 4a. Normalized Thermal Reactor Response to a Reactivity Step Change of -0.005 occurring at $t=0.40$. $\Delta t=0.8 \mathrm{sec}$ 


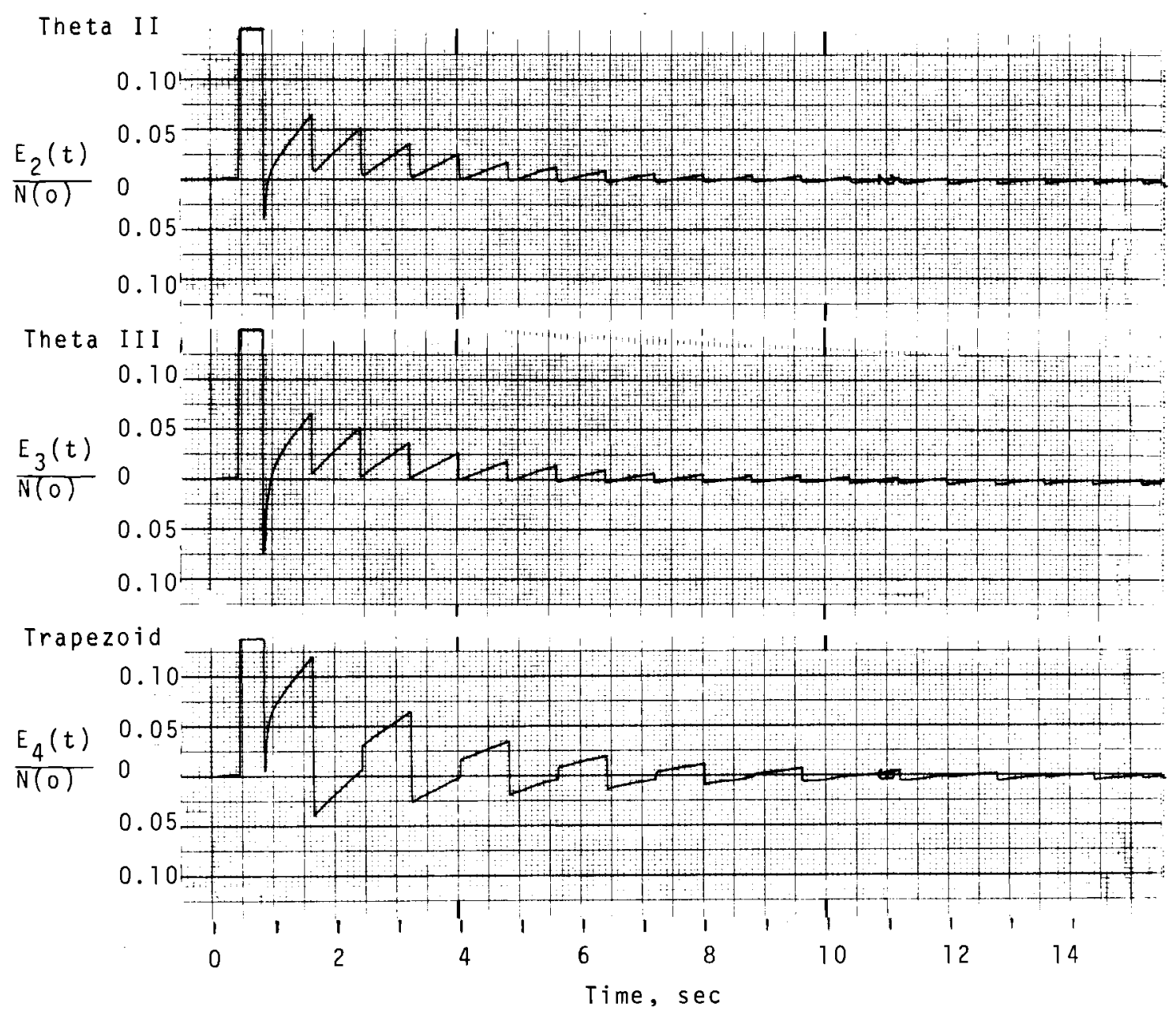

FIGURE 4b. Error Signals 

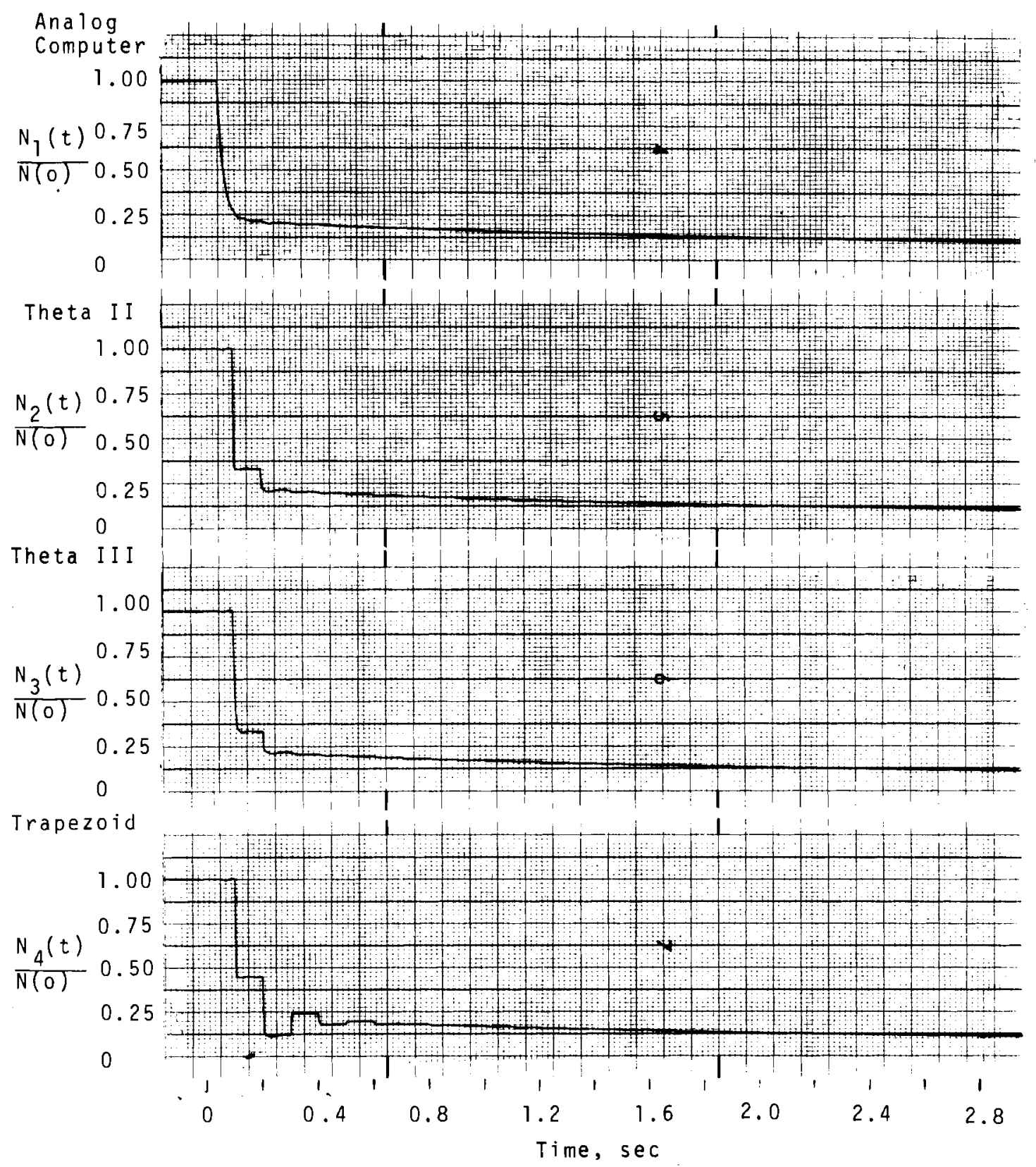

FIGURE 5a. Normalized Thermal Reactor Response to a Reactivity Step Change of -0.020 occurring at $t=0.05$. $\Delta t=0.1 \mathrm{sec}$ 


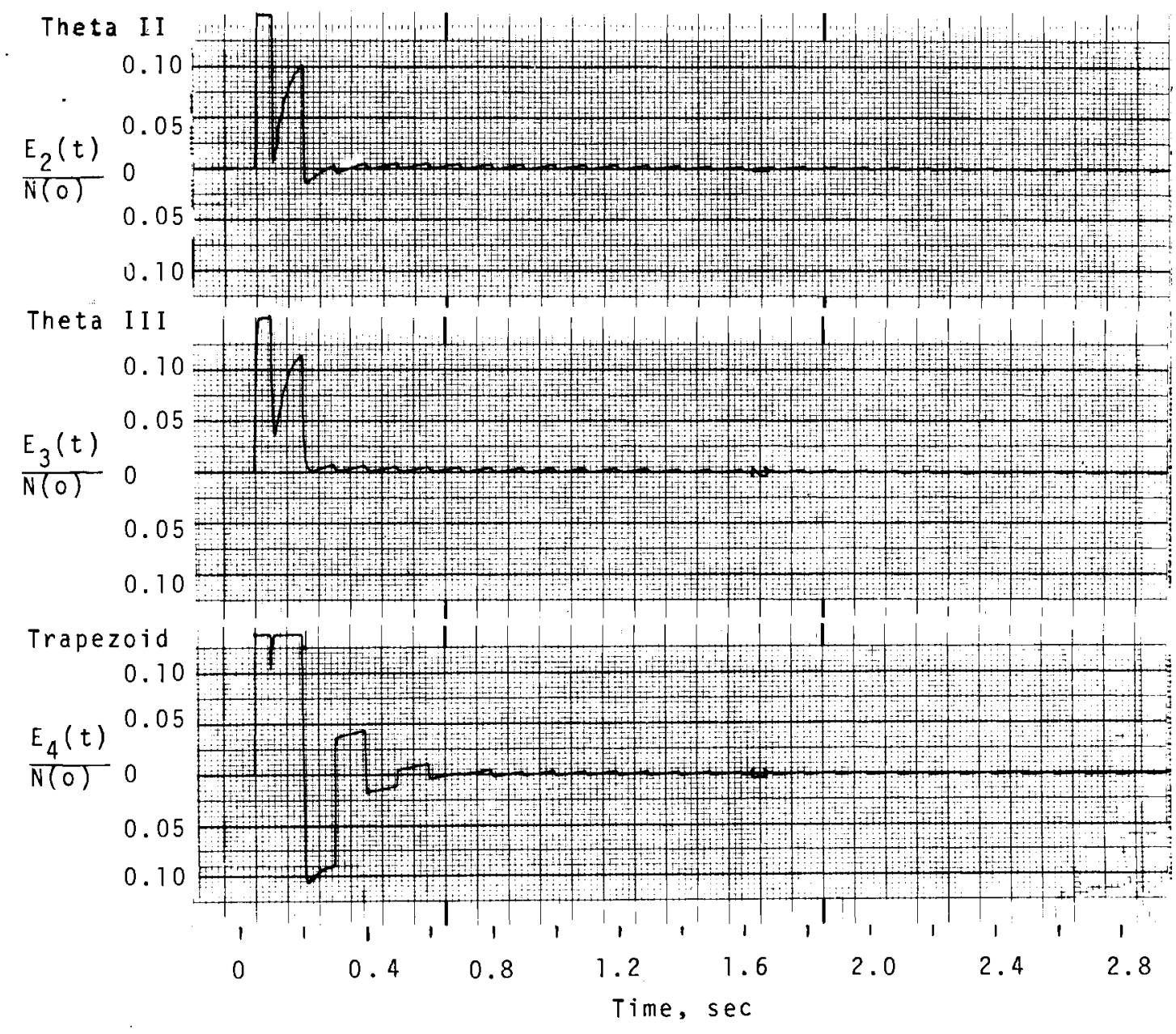

FIGURE 5b. Error Signals 

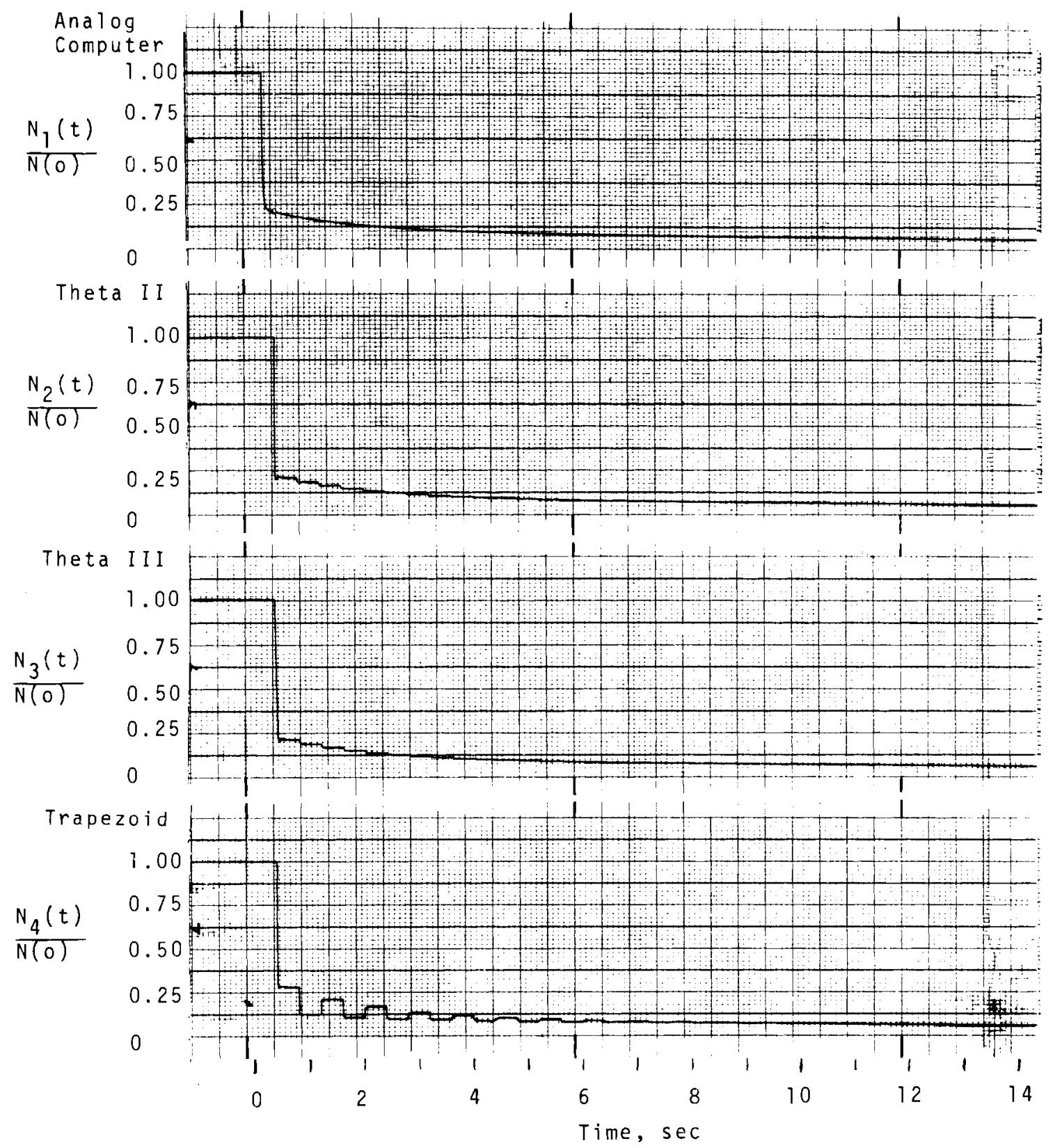

FIGURE 6a. Normalized Thermal Reactor Response to a Reactivity Step Change of -0.020 occurring at $t=0.20$. $\Delta t=0.4 \mathrm{sec}$ 


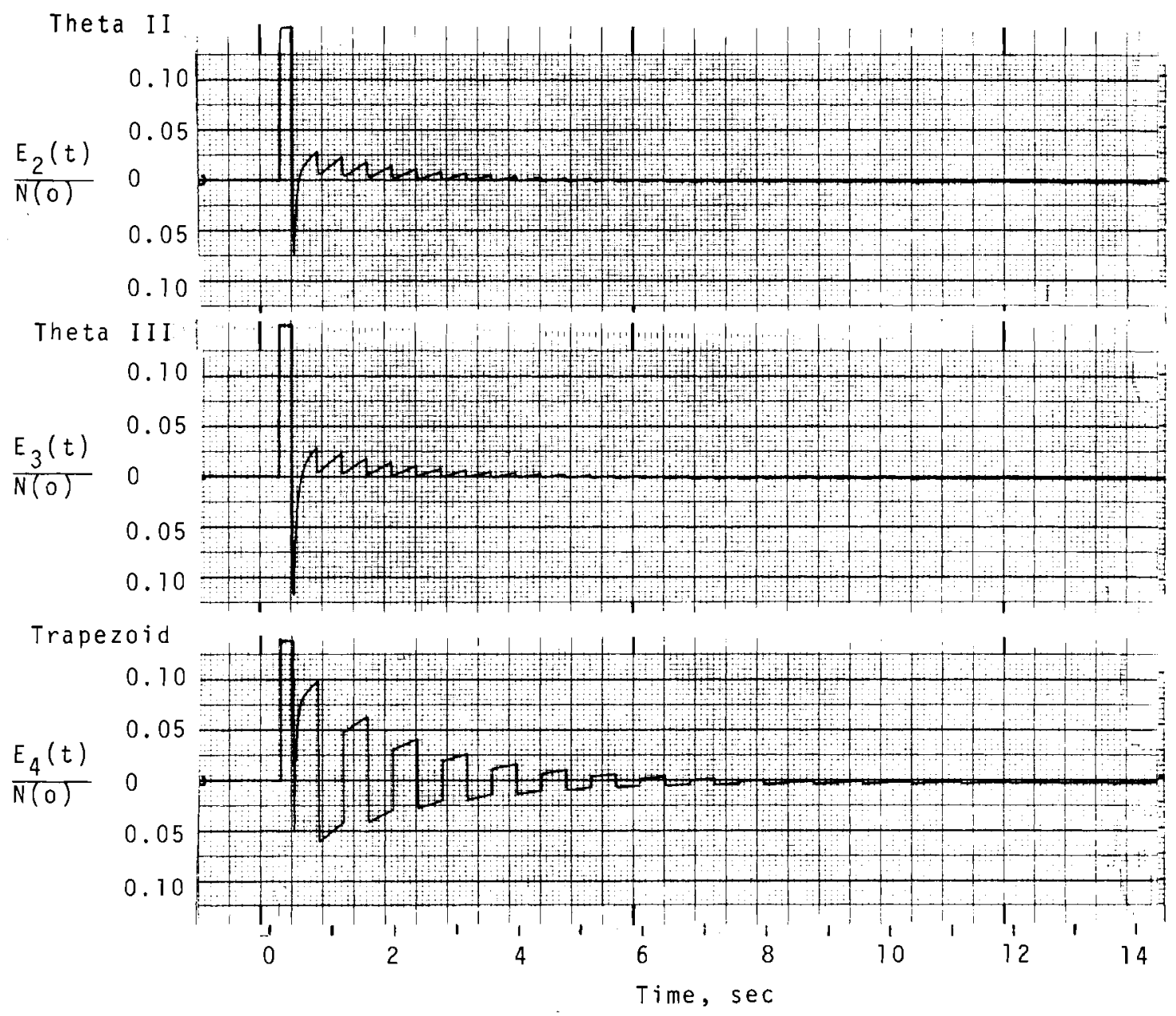

FIGURE 6b. Error Signals 
BNWL -940

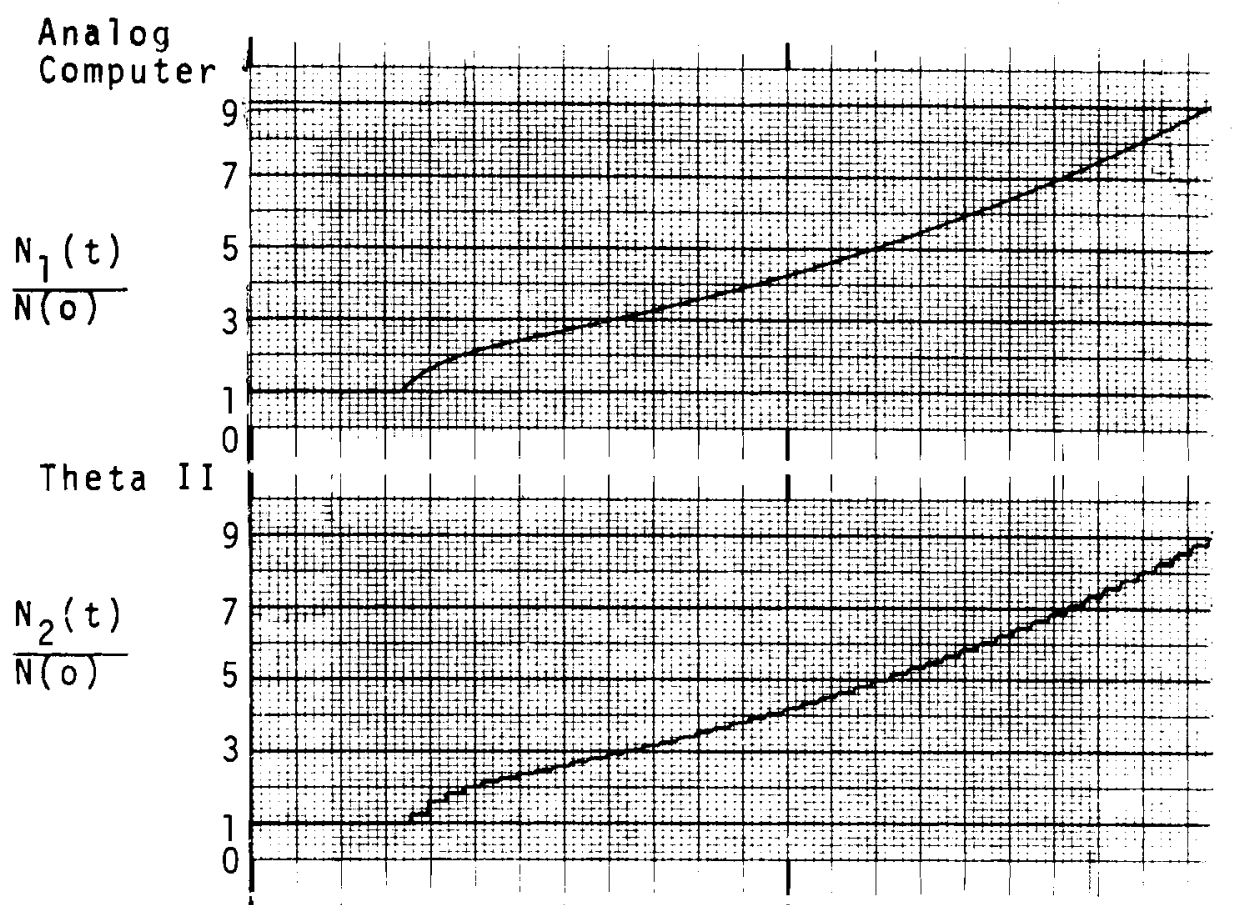

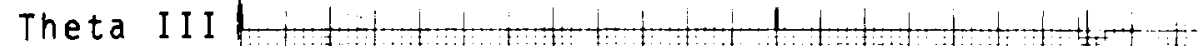

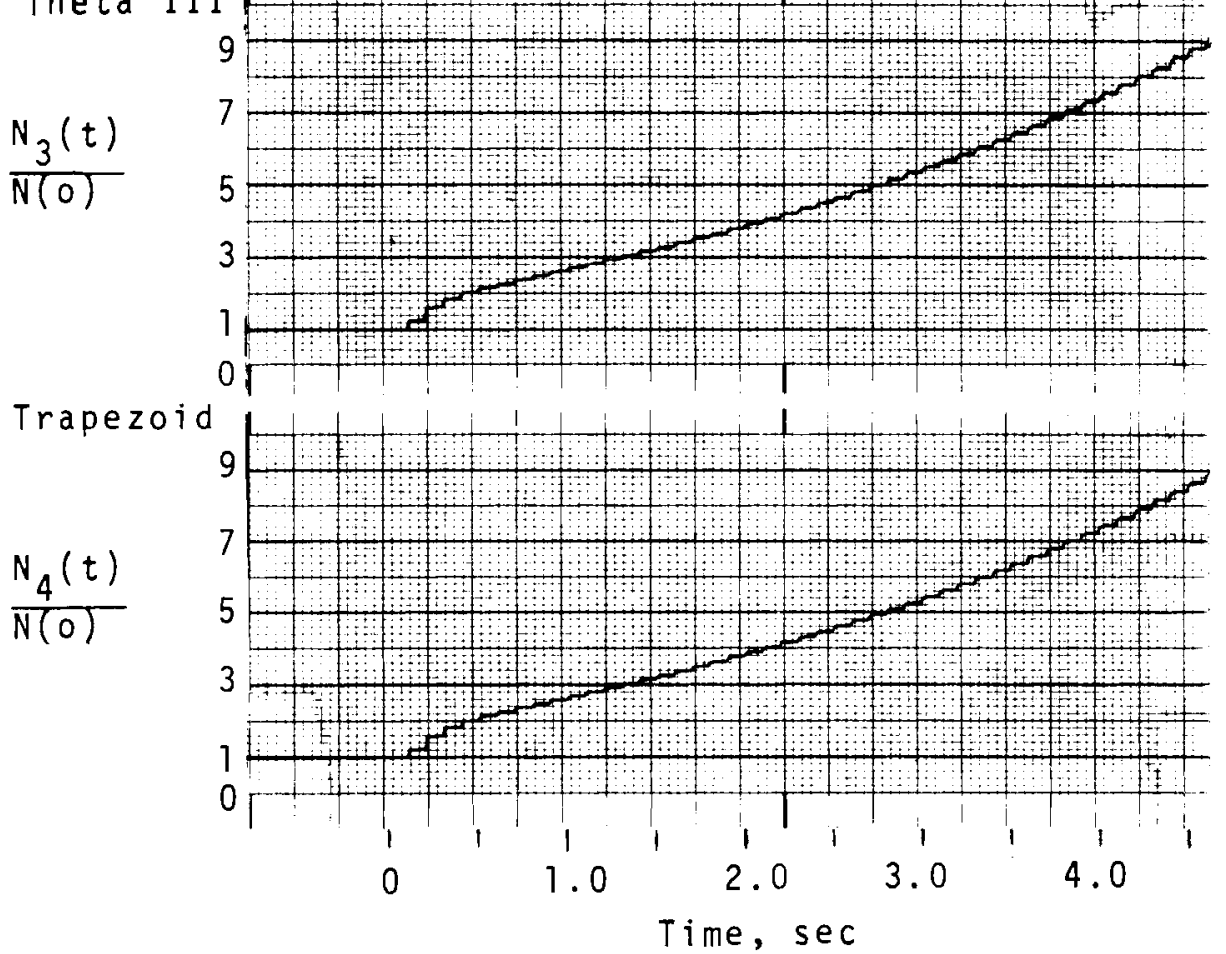

EIGURE 7a. Normalized Thermal Reactor Response to a Reactivity Step Change of +0.003 occurring at $t=0.05$. $\Delta t=0.1 \mathrm{sec}$ 
Theta II

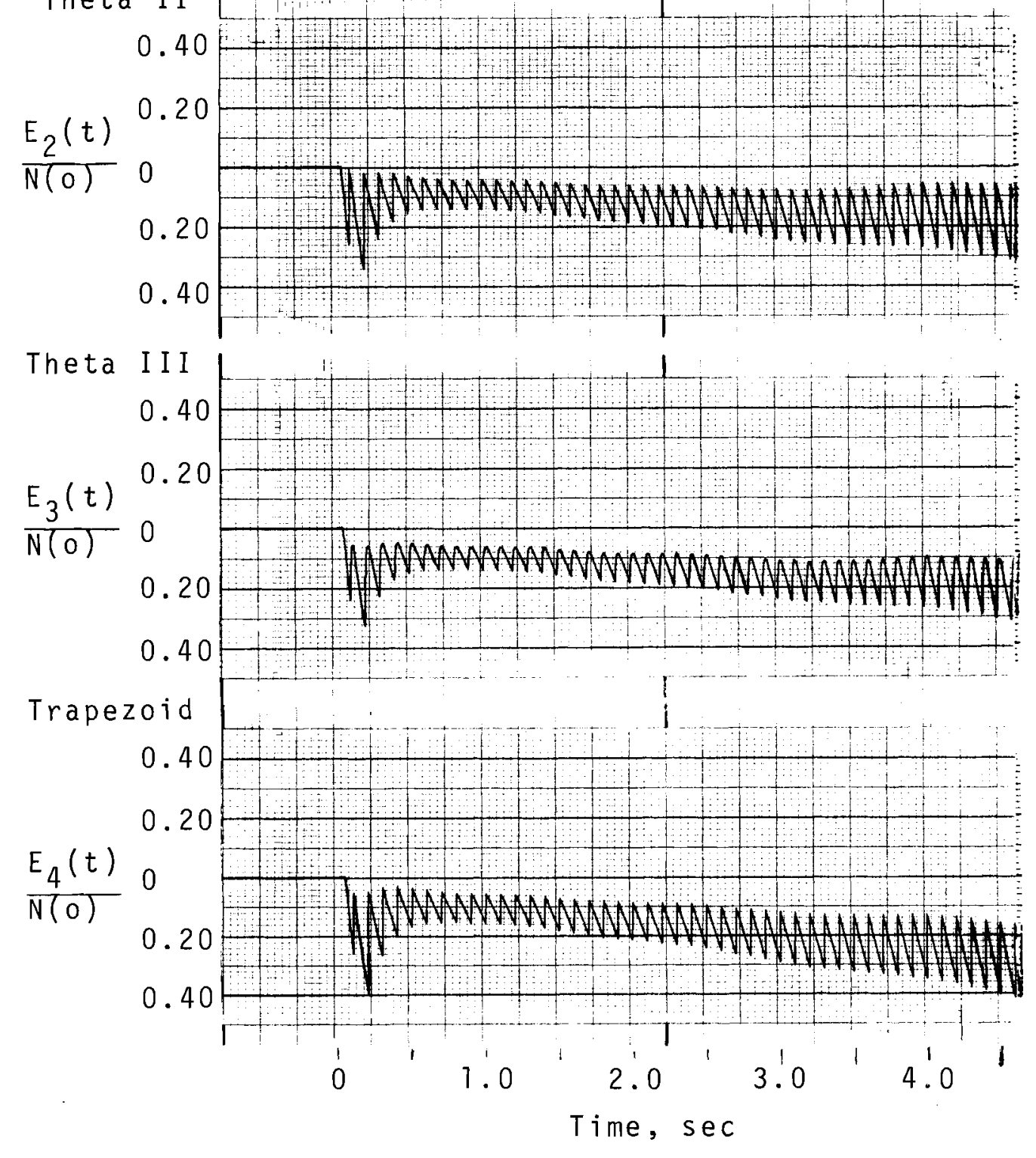

FIGURE 7b. Error Signals 


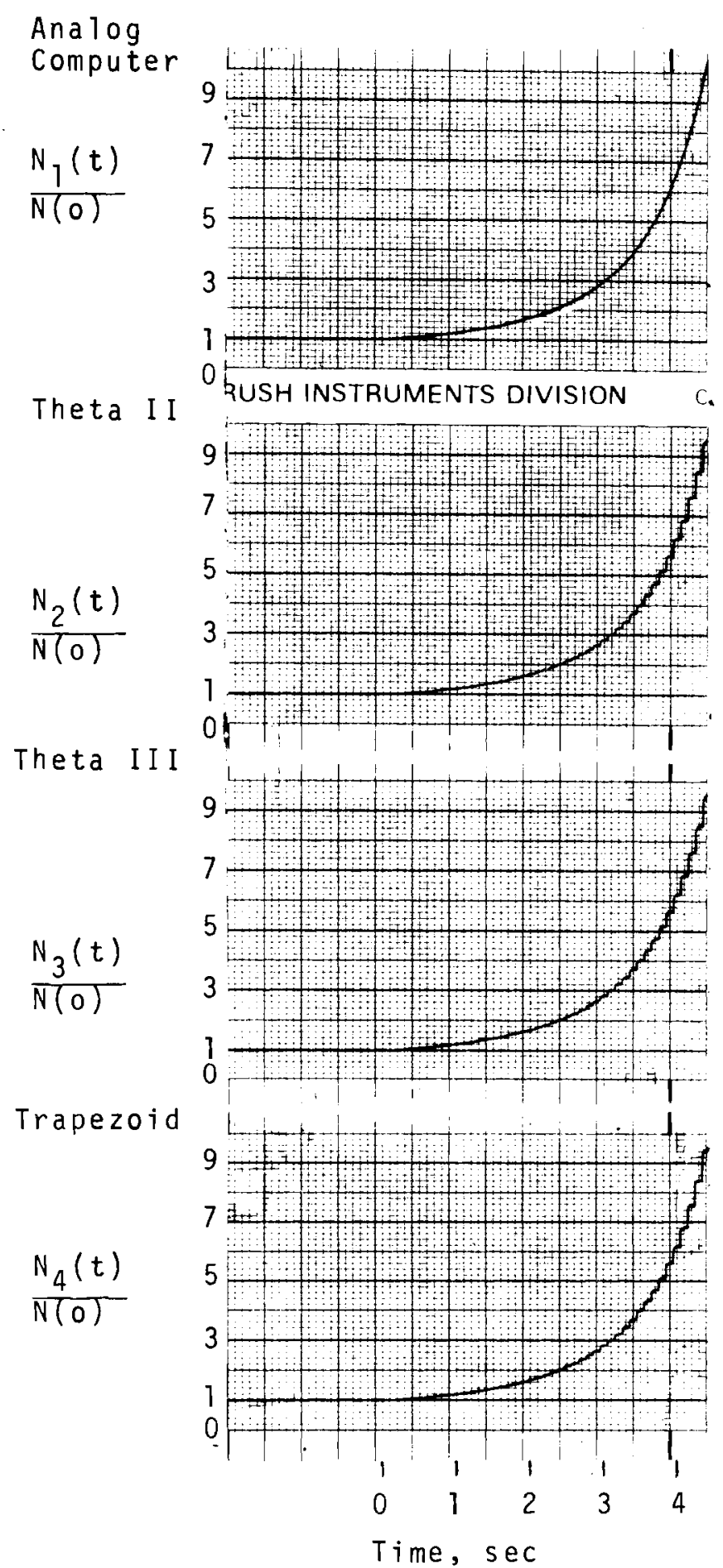

FIGURE 8a. Normalized Thermal Reactor Response to a Reactivity Ramp Input of $+0.001 t$ occurring at $t=0$. $\Delta t=0.1 \mathrm{sec}$ 


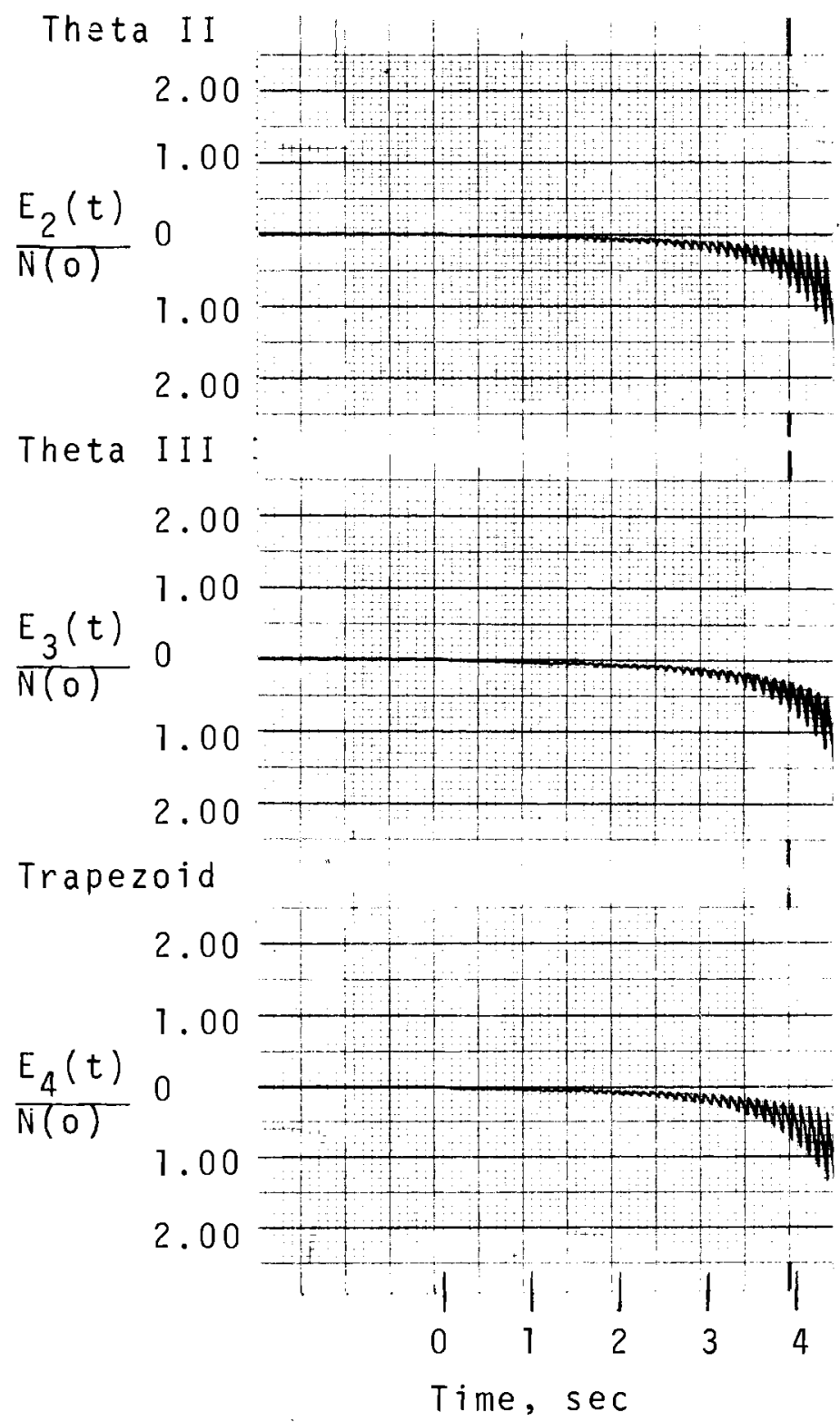

FIGURE 8b. Error Signals for Figure $8 a$ 


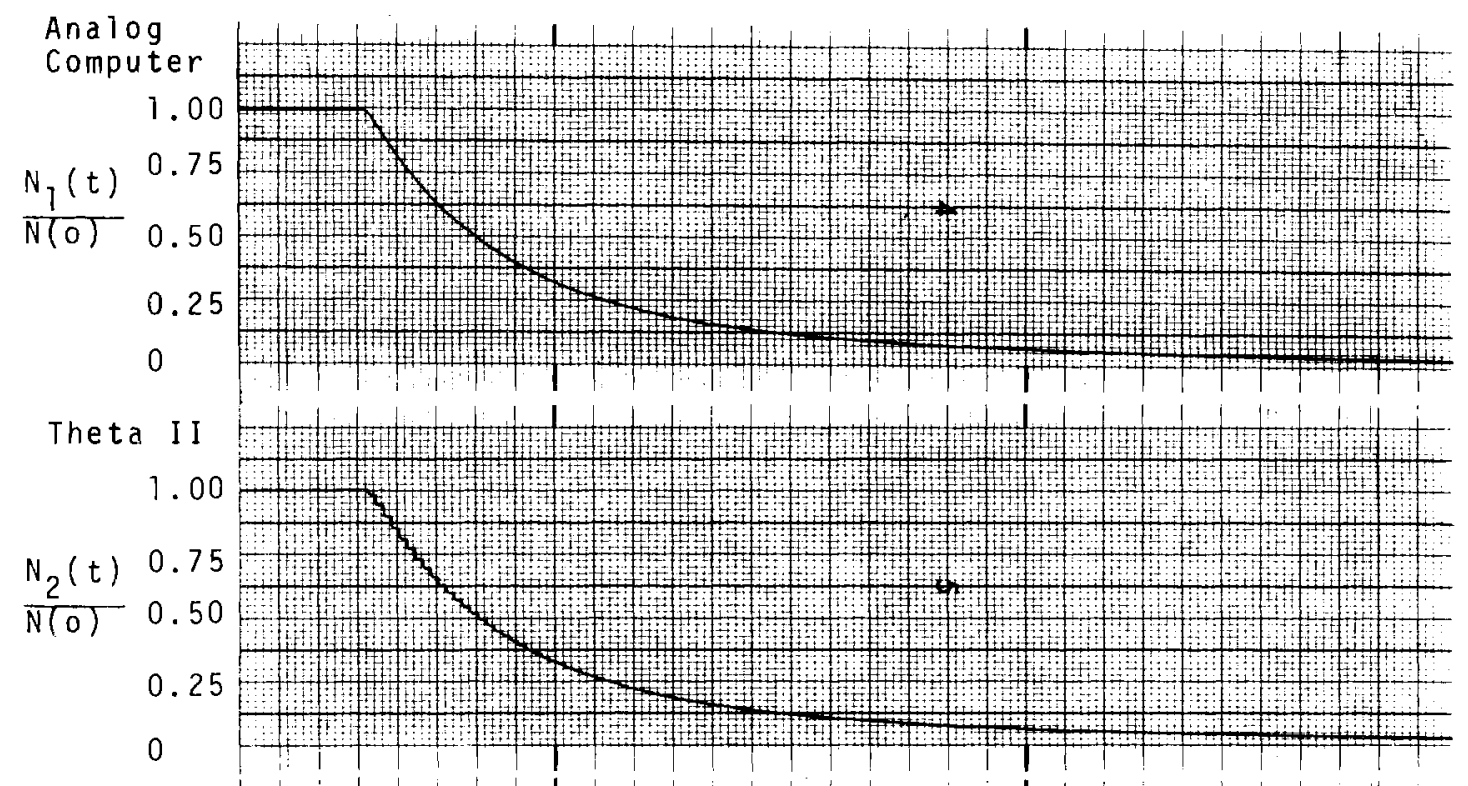

Theta III

1.00

$N_{3}(t) \quad 0.75$

$\overline{N(0)} 0.50$

0.25

0
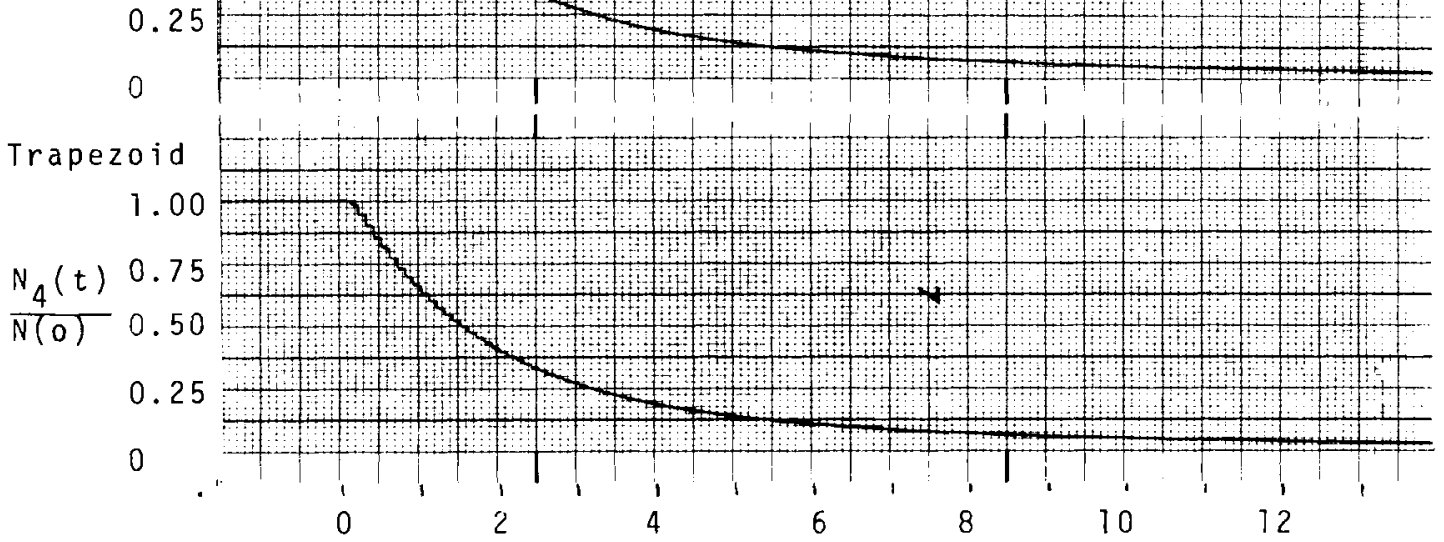

Time, sec

FIGURE 9a. Normalized Thermal Reactor Response to a Reactivity Ramp Input of $-0.003 t$ occurring at $t=0$. $\Delta t=0.1 \mathrm{sec}$ 


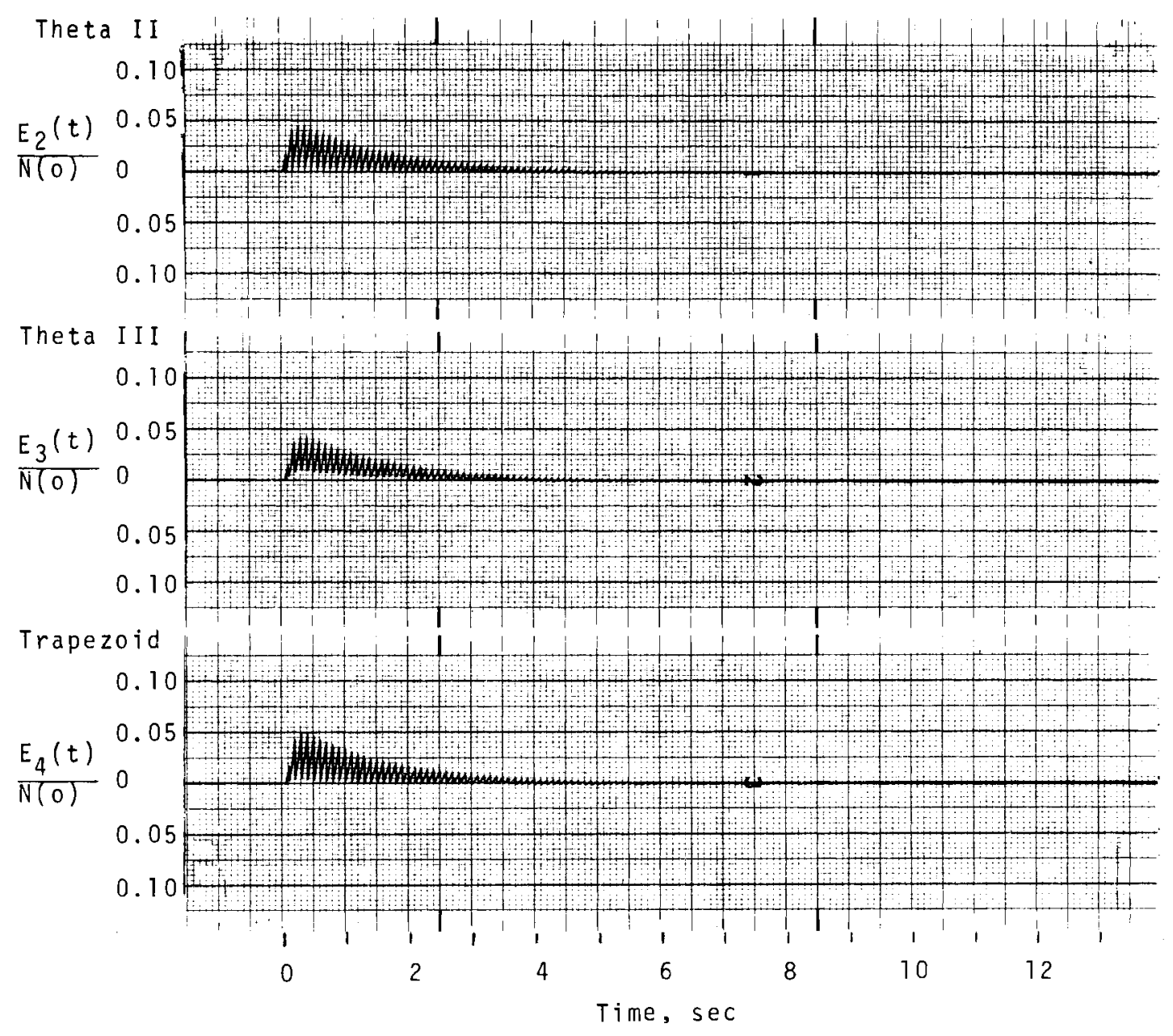

FIGURE 9b. Error Signals for

Figure $9 a$ 
size would be determined by the frame time of the digital portion of the entire simulation. However, roundoff error could further restrict the minimum $\Delta t$, especially with fixed-point arithmetic.

The PDP-7 solution time required by each method is given in Table 3 , along with the calculation times of various phases of the solution. Programming was done in symbolic assembly language. The PDP-7 is an 18-bit octal fixed-point computer with a cycle time of $1.75 \mathrm{\mu sec}$. More information about this computing system can be found in Reference 4.

Table 3 shows that a three-delay-group model requires a maximum PDP-7 frame time of $2.40 \mathrm{msec}$ with Theta I or II and 1.34 msec with Theta III. Corresponding times for a sixdelay-group model would be 3.93 and $1.94 \mathrm{msec}$. A frame time of $3.20 \mathrm{msec}$ has been achieved by Porsching(1) on a Philco 2000-212 computer for a six-delay-group model using Theta I. A Univac 1108 computer produced frame times of 0.780 and $0.414 \mathrm{msec}$ for Theta II and Theta III, respectively, with a reactivity input of 0.0037 and a three-delay-group model.

The Theta II variation proved to be as accurate as Theta II in the calculation of rapidly changing neutron levels, while Theta II was shown to be superior in the case of slow, long-term level changes. Some advantage could thus be gained by selecting Theta II or Theta II according to the anticipated rate of change of the neutron level. Such a program, called Theta Selective, was written with typical results listed in Table 4. In this program, Theta II was used to calculate $\mathrm{N}^{\mathrm{j}+1}$ unless either of the following two conditions prevailed, in which case Theta III was selected:

$$
\left|\rho^{j+1}-\rho^{j}\right| \geq 0.001 ;
$$

or $(b)$

$$
\left|\frac{N^{j}-N^{j-1}}{N^{j-1}}\right| \geq 0.1
$$


TABLE 3. PDP-7 Solution Times for Theta Methods and Trapezoidal Rule: Three-Delay-Group Thermal Reactor Kinetics

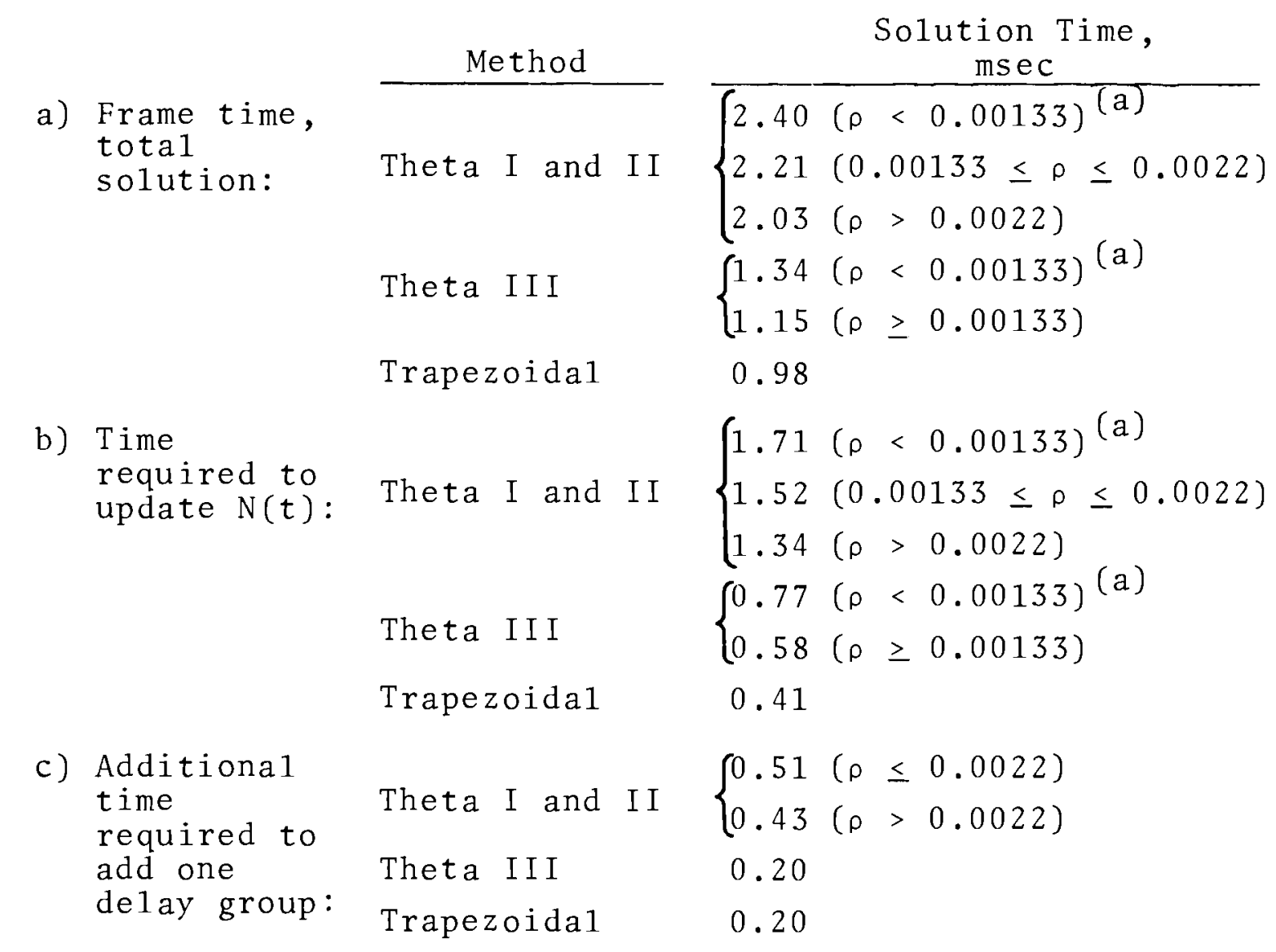

a. Reactivity break-point based on a time step ( $\Delta t)$ of 0.1 sec. A larger time step would cause an increase in this break point; e.g., if $\Delta t>0.1$, then Theta II frame time $=2.40$ msec if $\rho<\rho_{k}$, where $\rho_{k}>0.00133$.

The comparison numbers are not necessarily optimal but were chosen to give approximately the desired effect. Since the frame time of Theta II is approximately twice that of Theta III, the time step used by Theta II $\left(\Delta t_{2}\right)$ was also twice that used by Theta III $\left(\Delta t_{3}\right)$. In this manner the total percentage of simulation time consumed by the kinetics equations was held nearly constant. By using the faster Theta III variation and the smaller time step for calculation 
TABLE 4. Thermal Reactor Response to a Reactivity Step Change of -0.005 occurring at $t=0.025$; Theta Selective. $\Delta t_{3}=0.05 ; \Delta t_{2}=0.10 \mathrm{sec}$

$$
\begin{aligned}
& 100 \Delta t=5.00 \\
& 1000 \rho(0)=0.00 \\
& 1000 \rho(0+)=-5.00 \\
& 1000 \text { Times S1ope of } \rho \text { Ramp }=0.00
\end{aligned}
$$

\begin{tabular}{|c|c|c|c|c|c|}
\hline & & & & Ineta & Analyticas \\
\hline $100 \mathrm{~T}$ & 0.1 C 1 & $0.1 \quad \mathrm{C} 2$ & $\mathrm{C} 3$ & $10 \mathrm{~N}$ & $10 \mathrm{~N}$ \\
\hline 0.00 & 100.81 & 383.83 & 379.64 & 400.00 & 400.00 \\
\hline 5.00 & 100.81 & 383.70 & 378.77 & 326.41 & 326.71 \\
\hline 10.01 & 100.79 & 383.46 & 375.08 & 253.92 & 254.21 \\
\hline 15.01 & 100.77 & 383.09 & 369.97 & 225.79 & 226.18 \\
\hline 20.02 & 100.74 & 382.73 & 364.44 & 214.21 & 214.52 \\
\hline 30.03 & 100.68 & 382.12 & 353.22 & 205.66 & 205.53 \\
\hline 40.04 & 100.62 & 381.38 & 342.38 & 201.06 & 200.83 \\
\hline 50.05 & 100.56 & 380.65 & 332.01 & 197.11 & 196.87 \\
\hline 60.06 & 100.50 & 379.92 & 322.08 & 193.31 & 193.12 \\
\hline 70.07 & 100.44 & 379.19 & 312.59 & 189.72 & 189.57 \\
\hline 80.08 & 100.38 & 378.45 & 303.50 & 186.26 & 186.17 \\
\hline 90.09 & 100.32 & 377.72 & 294.83 & 182.98 & 182.93 \\
\hline 100.10 & 100.26 & 376.99 & 286.52 & 179.79 & 179.77 \\
\hline 110.11 & 100.20 & 376.26 & 278.59 & 176.78 & 176.76 \\
\hline 120.12 & 100.13 & 375.53 & 270.99 & 173.95 & \\
\hline 130.13 & 100.07 & 374.79 & 263.73 & 171.17 & 171.10 \\
\hline 140.14 & 100.01 & 374.06 & 256.79 & 168.56 & \\
\hline 150.15 & 99.94 & 373.33 & 250.15 & 165.93 & 165.91 \\
\hline 160.16 & 99.88 & 372.60 & 243.79 & 163.53 & \\
\hline 170.16 & 99.81 & 371.74 & 237.71 & 161.17 & 161.14 \\
\hline 180.17 & 99.73 & 370.89 & 231.89 & 158.87 & \\
\hline 190.13 & 99.66 & 370.03 & 226.32 & 156.73 & 156.73 \\
\hline 200.19 & 99.59 & 369.18 & 220.98 & 154.59 & \\
\hline 210.20 & 99.51 & 368.32 & 215.88 & 152.56 & 152.63 \\
\hline 220.21 & 99.44 & 367.47 & 211.00 & 150.63 & \\
\hline 230.22 & 99.36 & 366.61 & 206.31 & 148.77 & 148.88 \\
\hline 240.23 & 99.29 & 365.76 & 201.83 & 147.00 & \\
\hline 250.24 & 99.22 & 364.91 & 197.54 & 145.24 & 145.41 \\
\hline 260.25 & 99.15 & 364.05 & 193.43 & 143.52 & \\
\hline 270.26 & 99.07 & 363.20 & 189.49 & 142.03 & 142.20 \\
\hline 280.27 & 99.00 & 362.34 & 185.72 & 140.48 & \\
\hline 290.28 & 98.93 & 361.49 & 182.10 & 139.03 & \\
\hline 300.29 & 98.85 & 360.63 & 178.65 & 137.59 & 137.78 \\
\hline
\end{tabular}

Theta Analytical 
of sudden neutron level changes, more and closer points on the transient curve could be obtained. When the power level was changing slowly, the larger time step was used to take advantage of the now-superior accuracy of the Theta II variation. The Theta Selective comparison instructions added less than 100 usec per iteration to the total solution time.

\section{REACTIVITY FEEDBACK CONSIDERATIONS}

A Doppler feedback term, $\rho_{f b}$, was added to the total reactivity input to the thermal reactor model. The 2133 analog computer generated this term continuously as a function of the neutron level. Identical feedback functions were provided for each of the digital solutions and the analog solution. Typical results are shown in Figure 10.

This hybrid computation did not require any modifications in the digital programs, since they were already monitoring an analog voltage for the reactivity input. However, some problems would occur if the feedback reactivity were to be calculated digitally. Namely, $\rho_{\mathrm{fb}}^{\mathrm{j}+1}$ and $\mathrm{N}^{j+1}$ become functions of each other, and their interdependence cannot be simply resolved. Since the feedback reactivity cannot change abruptly, $\rho_{\mathrm{fb}}^{j+1}$ could be predicted fairly accurately by a linear extrapolation of its last two points in advance of the calculation of $\mathrm{N}^{\mathrm{j}+1}$ and then corrected after $\mathrm{N}^{\mathrm{j}+1}$ has been calculated. Alternatively, explicit (backward-difference) integration formulae could be used to predict new fuel and coolant temperatures and hence new feedback reactivity values. Similar techniques could be used for other types of reactivity feedback.

\section{FAST REACTOR KINETICS}

The Theta III and trapezoidal methods were applied to the kinetics equations of a fast reactor with a mean effective neutron lifetime $\left(l^{*}\right)$ of $3.5 \times 10^{-7} \mathrm{sec}$. Frame times 


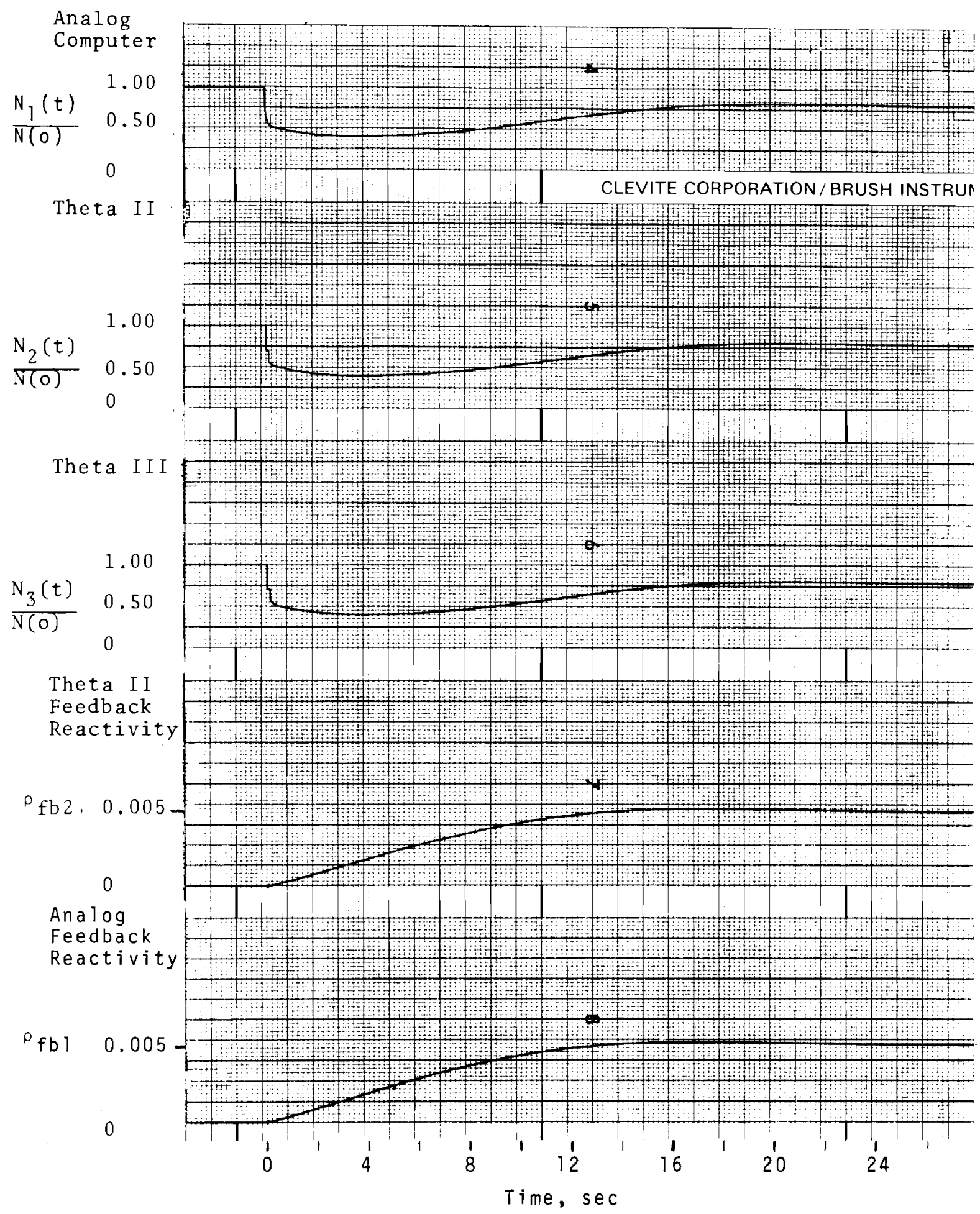

FIGURE 10a. Normalized Thermal Reactor Response to a Reactivity Step Change of -0.005 occurring at $t=0.05$, with Doppler Feedback. $\Delta t=0.1 \mathrm{sec}$ 


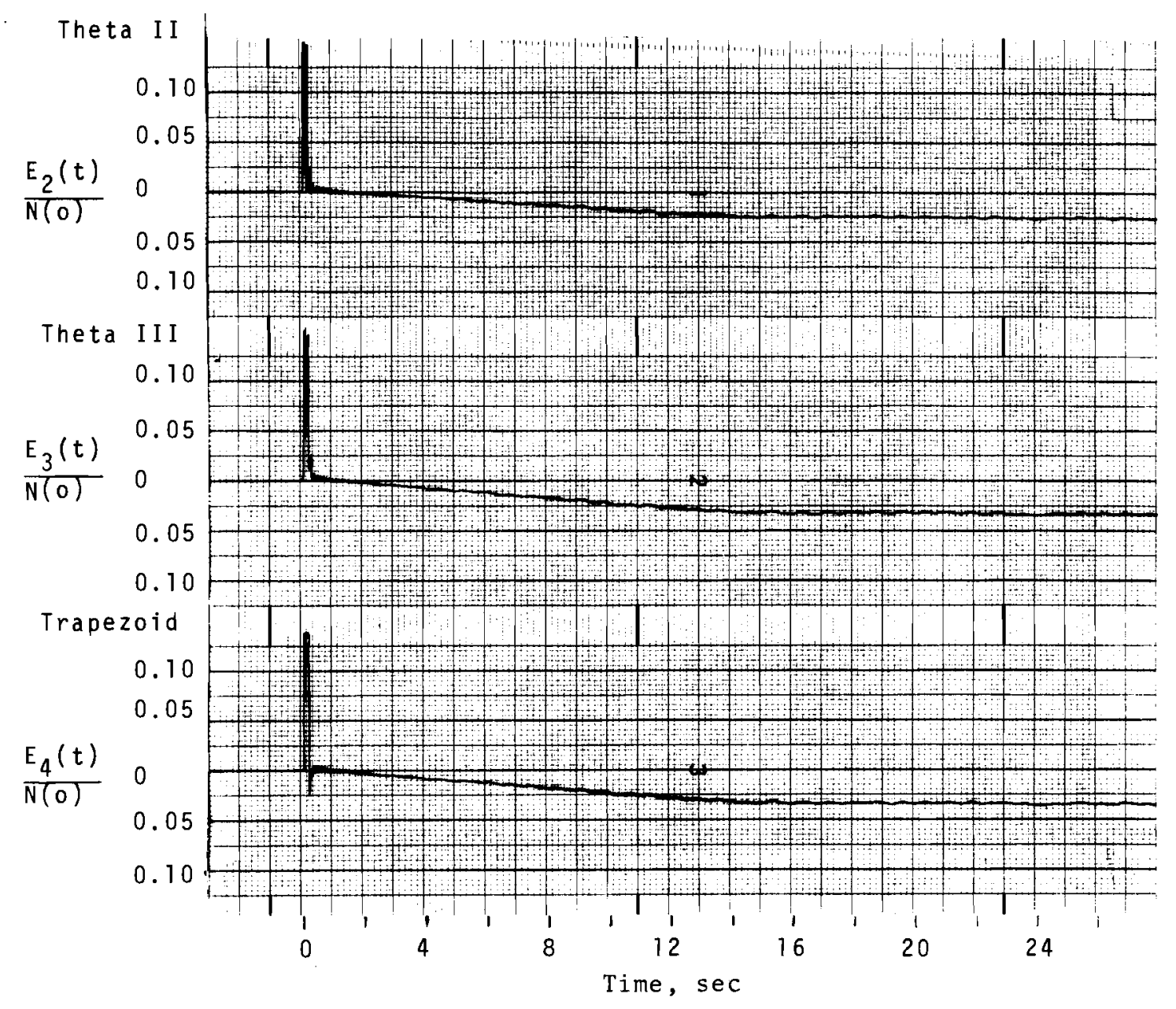

FIGURE 10b. $\begin{aligned} & \text { Error Signals for } \\ & \text { Figure 10a }\end{aligned}$ 
and computation times were similar to those listed for the thermal kinetics problems. Table 5 is a listing of the two digital solutions to a reactivity step of -0.005 using a time step of $0.1 \mathrm{sec}$, together with a set of approximate points taken from an analog computer solution of the same problem. The time step was changed to $0.4 \mathrm{sec}$, yielding the solutions listed in Table 6. In each case the digital solutions were both quite accurate and nearly identical. A constant value of $\theta_{1}^{j}=\theta_{1}^{j+1}=0.75$ was inserted into the equations, and again the results did not change significantly. The Theta III and trapezoidal solutions remained well matched for all of the reactivity functions selected, although a small difference gradually developed with increasing positive reactivity values such that Theta III was slightly more accurate. The reason for these rather surprising results can be better understood by making an approximate analysis of the Theta equations. This is done in Appendix B.

TABLE 5. Fast Reactor Response to a Reactivity step Change of -0.005 occurring at $t=0.05$ : Theta Method Test Number 3. $\Delta t=0.1 \mathrm{sec}$

\begin{tabular}{cccc}
$\begin{array}{c}\text { Time, } \\
\text { sec }\end{array}$ & $\begin{array}{c}\text { Trapezoidal } \\
\text { Rule }\end{array}$ & $\begin{array}{c}\text { Analog } \\
\text { Theta III }\end{array}$ & $\begin{array}{c}\text { Computer } \\
\text { Solution }\end{array}$ \\
\cline { 2 - 3 } 0.00 & $100 \mathrm{~N}$ & $100 \mathrm{~N}$ & $100 \mathrm{~N}$ \\
0.10 & 200.00 & 200.00 & 200.00 \\
0.20 & 77.26 & 77.14 & 76.80 \\
0.30 & 75.26 & 75.38 & 75.10 \\
0.40 & 73.81 & 73.69 & 73.50 \\
0.50 & 71.95 & 72.08 & 72.00 \\
0.60 & 70.69 & 70.54 & 70.60 \\
0.70 & 68.95 & 69.08 & 69.20 \\
0.80 & 67.85 & 67.69 & 67.80 \\
0.90 & 66.21 & 66.36 & 66.50 \\
1.00 & 65.25 & 65.09 & 65.20 \\
1.10 & 63.72 & 63.88 & 63.90 \\
1.20 & 62.87 & 62.72 & 61.60 \\
1.30 & 61.45 & 61.61 & 60.50 \\
1.40 & 60.73 & 60.56 & 59.40 \\
1.50 & 59.37 & 59.55 & 58.40 \\
1.60 & 58.74 & 58.58 & 57.50 \\
1.70 & 57.51 & 57.65 & 56.60 \\
1.80 & 56.93 & 56.78 & 55.80 \\
1.90 & 55.78 & 55.93 & 55.00 \\
2.00 & 55.27 & 55.13 & 54.20 \\
2.10 & 54.20 & 54.35 & 53.50 \\
2.20 & 53.77 & 53.60 & 52.80 \\
2.30 & 52.75 & 52.89 & 52.10 \\
2.40 & 52.38 & 52.21 & 51.50 \\
2.50 & 51.42 & 51.56 & 50.90
\end{tabular}


TABLE 6. Fast Reactor Response to a Reactivity Step Change of -0.005 occurring at $t=0.20$ : Theta Method Test Number 3. $\Delta t=0.4 \mathrm{sec}$

\begin{tabular}{|c|c|c|c|}
\hline $\begin{array}{c}\text { Time, } \\
\text { sec } \\
\end{array}$ & $\begin{array}{c}\text { Trapezoidal } \\
\text { Rule } \\
\end{array}$ & Theta I I & $\begin{array}{l}\text { Analog } \\
\text { Computer } \\
\text { Solution } \\
\end{array}$ \\
\hline $\mathrm{T}$ & $100 \mathrm{~N}$ & $100 \mathrm{~N}$ & $100 \mathrm{~N}$ \\
\hline 0.00 & 200.00 & 200.00 & 200.00 \\
\hline 0.40 & 74.74 & 74.67 & 74.30 \\
\hline 0.80 & 68.43 & 68.50 & 68.10 \\
\hline 1.20 & 63.44 & 63.37 & 63.20 \\
\hline 1.60 & 59.05 & 59.11 & 59.00 \\
\hline 2.00 & 55.62 & 55.54 & 55.40 \\
\hline 2.40 & 52.50 & 52.57 & 52.40 \\
\hline 2.80 & 50.12 & 50.05 & 50.00 \\
\hline 3.20 & 47.89 & 47.93 & 47.90 \\
\hline 3.60 & 46.19 & 46.12 & 46.10 \\
\hline 4.00 & 44.53 & 44.58 & 44.40 \\
\hline 4.40 & 43.31 & 43.24 & 43.00 \\
\hline 4.80 & 42.03 & 42.08 & 41.90 \\
\hline 5.20 & 41.14 & 41.05 & 40.90 \\
\hline 5.60 & 40.11 & 40.15 & 40.00 \\
\hline 6.00 & 39.43 & 39.36 & 39.20 \\
\hline
\end{tabular}

\section{CONCLUSIONS}

The introduction of $\theta_{1}^{j+1}$ into the Theta equations resulted in a basic improvement in the method. With thermal reactor parameters, the Theta II variation displayed superior accuracy over trapezoidal integration but required more than twice the solution time. Theta III was more accurate than the trapezoidal rule while requiring only a slightly longer solution time; Theta III was less accurate than Theta II. In general, the superiority of the Theta methods was most noticeable when large negative reactivity steps were applied and when the integration time step was large.

Theta Selective combined the advantages of Theta II and Theta III with only a small increase in the effective frame time. This technique is recommended for complex simulations of thermal reactor systems in which the kinetics 
equations are a small fraction of the total digital simulation. Strict use of Theta II would be desirable if the digital part of the total simulation is small enough to permit it. In either case, the frame time is small enough and the accuracy is good enough to provide an excellent real-time or faster kinetics simulation.

Because of the nature of the Theta equations, the fast reactor parameters created a situation in which trapezoidal integration performed as well as Theta integration for most reactivity inputs. Thus, in fast reactor simulations requiring an absolute minimum overall frame time, trapezoidal integration would be recommended. In most cases, however, Theta III would be preferable here because of its slightly greater accuracy in response to positive reactivity inputs.

\section{LIST OF SYMBOLS}

$\underline{\text { Symbo1 }}$

$N(t)$

$C_{i}(t)$

G

B

$\beta_{i}$

${ }^{\lambda}$ i

$\ell^{*}$

$\rho$

$\rho_{f b}$

$\Delta \mathrm{t}$

${ }^{\theta}, \theta_{2}$
Definition

Neutron concentration (neutron $/ \mathrm{cm}^{3}$ ). Proportional to power level.

Concentration of ith delayed neutron precursor (nuclei $/ \mathrm{cm}^{3}$ )

Total number of delayed neutron groups

Total delayed neutron fraction (dimensionless)

Delayed neutron fraction from ith group

(dimensionless)

Decay constant of ith precursor $\left(\sec ^{-1}\right)$

Mean effective neutron lifetime (sec)

Total reactivity (dimensionless)

Doppler feedback reactivity (dimensionless)

Integration step size ( $\mathrm{sec}$ )

Weighting parameters, Theta method (dimensionless) 


\section{REFERENCES}

1. T. A. Porsching. The Numerical Solution of the Reactor Kinetics Equations by Difference Analogs: A Comparison of Methods, WAPD-TM-564. Westinghouse Electric Corporation, March 1966.

2. A. F. Henry and A. V. Vota. WIGL2: A Program for the Solution of the one-Dimensional, Two-Group, Space-Time Diffusion Equations Accounting for Temperature, Xenon, and Control Feedback, WAPD-TM-532. Westinghouse Electric Corporation, october 1965.

3. N. E. Carter. Unpublished Data. Pacific Northwest Laboratory, Richland, Washington. (Personal Communication.)

4. M. D. Erickson. The Battelle-Northwest Hybrid Computer System, BNWL-538. Pacific Northwest Laboratory, October 1967 . 


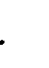

,

. 
APPENDICES 


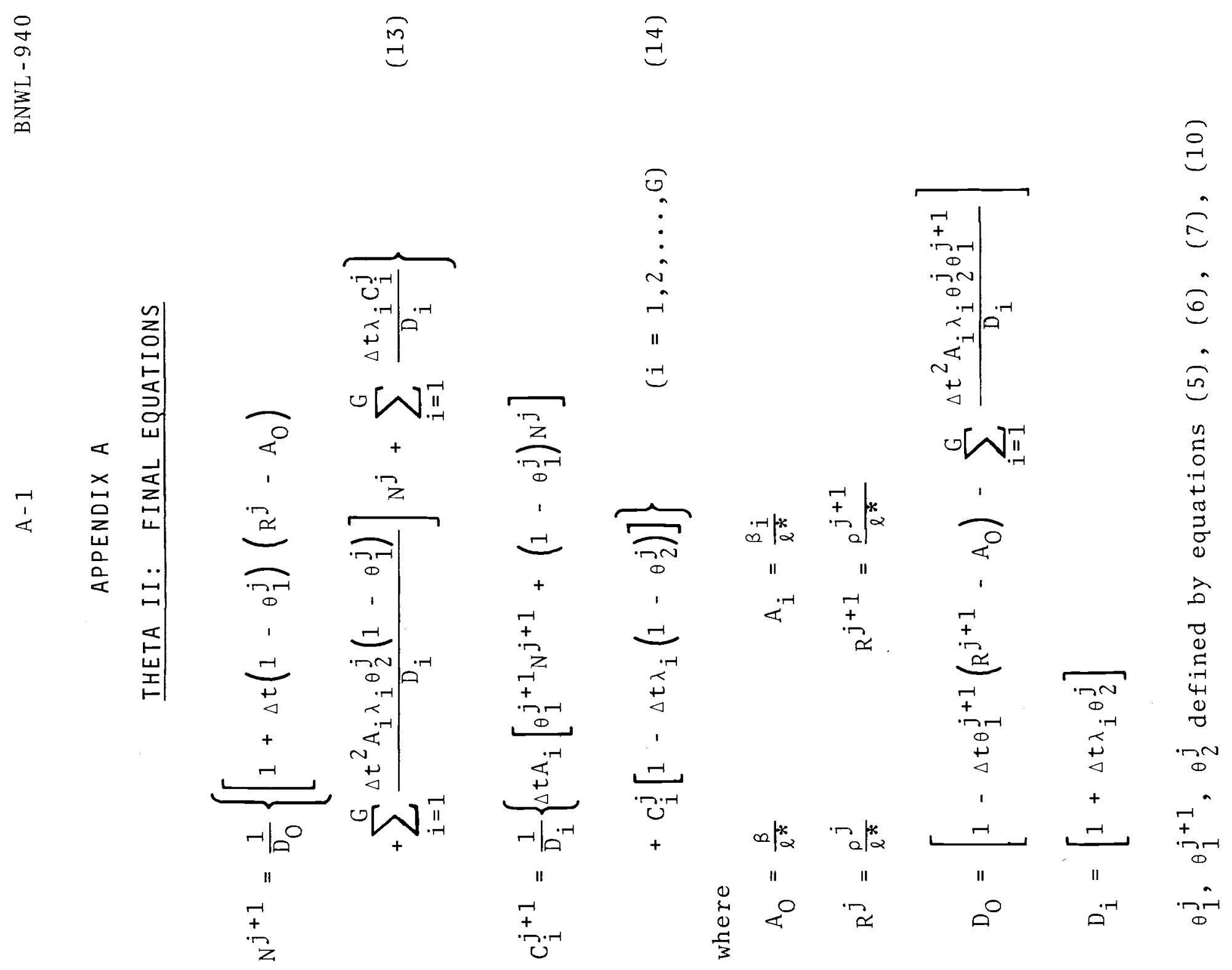




$$
\text { A }-2
$$

BNWL - 940

\section{OTHER VARIATIONS}

Theta I: Substitute $\theta_{1}^{j}$ in place of every $\theta_{1}^{j+1}$.

Theta III: $\theta_{2}^{j}=0.5$

Trapezoidal Rule: $\theta_{1}^{j}=\theta_{1}^{j+1}=\theta_{2}^{j}=0.5$ 


\section{APPENDIX B}

\section{FAST KINETICS SOLUTION ANALYSIS}

The lack of significant difference between the Theta and trapezoidal solutions in the fast reactor study can be better understood with the aid of the following approximate analysis of the Theta Equations (13) and (14).

First, we observe that the primary difference between the fast neutron constants and the thermal constants is the size of $\ell^{*}$. With the short life-time of the fast kinetics, the magnitude of $\left(R-A_{O}\right)$ is quite large (>9000 when $\left.\rho \leq 0\right)$ unless $\rho \simeq \beta$.

Now suppose that $\theta_{1}^{j}=\theta_{1}^{j+1}=\theta_{1}=0.5$ or some constant near 0.5 such that neither $\theta_{1}$ nor $\left(1-\theta_{1}\right)$ is excessively sma11. Trapezoidal integration meets this requirement. Next, if $\Delta t$ is large enough such that

$$
\left|\Delta t\left(1-\theta_{1}\right)\left(R^{j}-A_{0}\right)\right|>>1
$$

and

$$
\left|\Delta t \theta_{1}\left(R^{j+1}-A_{0}\right)\right|>>1,
$$

and yet $\Delta t$ is sma11 enough such that

$$
\left|\Delta t\left(1-\theta_{1}\right)\left(R^{j}-A_{0}\right)\right| \gg\left|\sum_{i=1}^{G} \frac{\Delta t^{2} A_{i} \lambda_{i} \theta_{2}^{j}\left(1-\theta_{1}\right)}{D_{i}}\right|
$$

and

$$
\left|\Delta t \theta_{1}\left(R^{j+1}-A_{0}\right)\right| \gg\left|\sum_{i=1}^{G} \frac{\Delta t^{2} A_{i} \lambda_{i} \theta_{2}^{j} \theta_{1}}{D_{i}}\right|
$$


then Equation (13) can be approximated by

$$
N^{j+1} \simeq-\left[\frac{1-\theta_{1}}{{ }_{1}}\right]\left[\frac{R^{j}-A_{O}}{R^{j+1}-A_{O}}\right] N^{j}-\left[\frac{1}{\theta_{1}\left(R^{j+1}-A_{O}\right)}\right]\left[\sum_{i=1}^{G} \frac{\lambda_{i} C_{i}^{j}}{D_{i}}\right]
$$

In the initial steady state, with $R^{j}=R^{j+1}=0$,

$$
N^{j+1}=N_{0} \simeq-\left[\frac{1-{ }_{1}}{{ }^{\theta} 1}\right] N_{0}+\left[\frac{1}{{ }^{\theta_{1} A_{0}}}\right]\left[\sum_{i=1}^{G} \frac{\lambda_{i} C_{i O}}{D_{i}}\right]
$$

Solving for the initial precursor density term:

$$
\sum_{i=1}^{G} \frac{\lambda_{i} C_{i O}}{D_{i}}=A_{0} N_{0}
$$

Thus the first iteration after a reactivity step change should produce

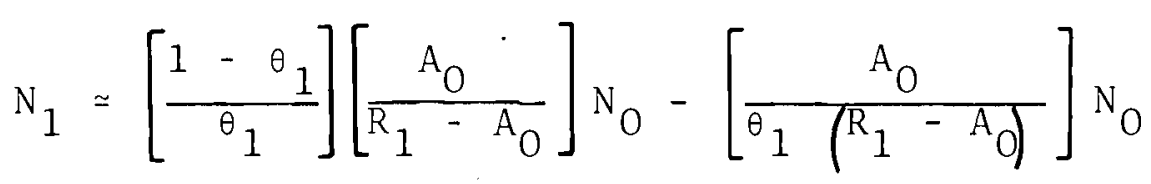

or

$$
N_{1} \simeq\left[\frac{A_{0}}{A_{0}-R_{1}}\right] N_{0}=\left[\frac{B}{\beta-\rho_{1}}\right] N_{O}
$$

This is the magnitude of the "prompt jump" given in nuclear engineering textbooks as the initial response to a step reactivity input.

Having achieved this degree of accuracy on the first iteration, the trapezoidal rule is then able to compute the remaining slowly changing portion of the transient quite easily. 
It shall now be shown that the Theta methods will also give approximately this same first point of the step response.

$$
\text { If } \omega_{1} \Delta t=\left(R-A_{0}\right) \Delta t \text { is large in magnitude }(>1) \text { and }
$$
negative in sign, then $\theta_{1}$ can be very accurately given by

$$
\theta_{1} \simeq \frac{\left(R-A_{0}\right) \Delta t+1}{\left(R-A_{0}\right) \Delta t}
$$

Substituting into Equation (13), one obtains:

$$
N^{j+1}=\left\{\frac{1+\Delta t\left(R^{j}-A_{O}\right)\left[1-\frac{\left(R^{j}-A_{O}\right) \Delta t+1}{\left(R^{j}-A_{O}\right) \Delta t}\right]}{1-\Delta t\left(R^{j+1}-A_{O}\right)\left[\frac{\left(R^{j+1}-A_{O}\right) \Delta t+1}{\left(R^{j+1}-A_{O}\right) \Delta t}\right]}\right\}_{N}^{j}
$$$$
+\left\{\frac{1}{1-\Delta t\left(R^{j+1}-A_{0}\right)\left[\frac{\left(R^{j+1}-A_{0}\right) \Delta t+1}{\left(R^{j+1}-A_{0}\right) \Delta t}\right]}\right\}\left\{\sum_{i=1}^{G} \frac{\Delta t \lambda_{i} C_{i}^{j}}{D_{i}}\right\}
$$

where the summation terms containing $\Delta t^{2}$ have again been neglected. Simplifying, one obtains 


$$
\begin{aligned}
N^{j+1}= & -\left[\frac{1+\Delta t\left(R^{j}-A_{O}\right)-\Delta t\left(R^{j}-A_{O}\right)-1}{\Delta t\left(R^{j+1}-A_{O}\right)}\right] N^{j} \\
& -\left[\frac{1}{\left(R^{j+1}-A_{O}\right)}\right]\left[\sum_{i=1}^{G} \frac{\lambda_{i} C_{i}^{j}}{D_{i}}\right] \\
N^{j+1}= & -\left[\frac{1}{R^{j+1}-A_{O}}\right]\left[\sum_{i=1}^{G} \frac{\lambda_{i} C_{i}^{j}}{D_{i}}\right]
\end{aligned}
$$

Initial values are

$N^{j+1}=N_{O}=\frac{1}{A_{O}} \sum_{i=1}^{G} \frac{\lambda_{i} C_{i O}}{D_{i}}$

$\sum_{i=1}^{G} \frac{\lambda_{i} C_{i O}}{D_{i}}=A_{0} N_{0}$

and the first iteration yields

$$
N_{1} \simeq-\left[\frac{A_{0}}{R_{1}-A_{O}}\right] N_{0}=\left[\frac{\beta}{\beta-\rho_{1}}\right] N_{0}
$$

which is the same "prompt jump" as that generated by the trapezoidal rule. 


\section{DISTRIBUTION}

No. of

Copies

OFFSITE

AEC Chicago Patent Group

G. H. Lee

AEC Division of Reactor Development and Technology Washington, D. C. 20545

M Shaw, Director, RDT Asst Dir for Nuclear Safety

Analysis \& Evaluation Br, RDT:NS

Environmental \& Sanitary Engrg $\mathrm{Br}, \mathrm{RDT}: \mathrm{NS}$

Research \& Development Br, RDT:NS

Asst Dir for Plant Engrg, RDT

Applications \& Facilities Br, RDT:PE

Components $\mathrm{Br}$, RDT:PE

Instrumentation \& Control Br, RDT:PE

Liquid Metal Systems Br, RDT:PE

Asst Dir for Program Analys is, RDT

Asst Dir for Project Mgmt, RDT

Liquid Metals Projects Br, RDT:PM

FFTF Project Manager, RDT:PM (3)

Asst Dir for Reactor Engrg

Control Mechanisms Br, RDT:RE

Core Design Br, RDT:RE (2)

Fue1 Fabrication $\mathrm{Br}$, RDT:RE

Fue 1 Handling $\mathrm{Br}$., RDT:RE

Reactor Vessels Br, RDT : RE

Asst Dir for Reactor Tech

Coolant Chemistry Br, RDT

Fue 1 Recycle Br, RDT

Fue1s \& Materials Br, RDT:RT

Reactor Physics Br, RDT:RT

Special Technology Br, RDT:RT

Asst Dir for Engrg Standards, RDT

AEC Division of Technical Information Extension

AEC Idaho Operations Office

Nuclear Technology Division

C. W. Bil1s, Director

AEC San Francisco Operations Office Director, Reactor Division 
No. of

Copies

4

AEC Site Representatives

Argonne National Laboratory

Atomics International

Atomic Power Development Assoc.

General Electric Co.

Atomics Power Development Assoc.

Document Librarian

2

Argonne National Laboratory

R. A. Jaross

LMFBR Program office

Atomics International

D. J. Cockeram

Liquid Metal Information Center

J. J. Droher

Babcock \& Wilcox Co.

Atomic Energy Division

S. H. Esleeck

G. B. Garton

Bechte1 Corporation

J. J. Teachnor, Project Administrator, FFTF

Combustion Engineering

1000 MWe Fol1ow-On Study

W. P. Staker, Project Manager

5

General Electric Co.

Advanced Products Operation

Kar1 Cohen

Bertram Wolfe

Nuclear Systems Programs

D. H. Ahmann

2

Gulf General Atomic Inc. General Atomic Div

D . Coburn 
No. of

Copies

1

2

1

1

1

10
Idaho Nuclear Corporation

D. R. deBoisblanc

Martin Marietta Corp.

A. I. Rubin, SCI SARE Library

PNL Representative

N. A. Hill (ZPR III)

Stanford University

Nuclear Division

Division of Mechanical Engrg

R. Sher

United Nuclear Corporation Research and Engineering Center

R. F. DeAnge 1 is

Westinghouse Electric Corp.

Atomic Power Division

Advanced Reactor Systems

J. C. R. Ke11y

ONSITE HANFORD

1

2

4

3

1

1
AEC Chicago Patent Group

R. K. Sharp (Richland)

AEC RDT Site Representative

P. G. Holsted

AEC Richland Operations Office FFTF Program

J. M. Shivley

C. L. Robinson

Batte1le Memorial Institute

Bechtel Corporation

D. H. Weiss (Rich1 and)

Douglas United Nuclear

C. F. Poor 
No. of

Copies

1

68
Westinghouse Electric Corp.

R. Strzelecki (Richland)

Batte11e-Northwest

L. E. Addison

R. C. Arnett

E. R. Astley

R. D. Benham

C. A. Bennett

R. A. Bennett

W. L. Bunch

R. A. Burnett

N. E. Carter

C. R. Cole

D. L. Condotta

G. M. Dalen

M. H. Deardorff

P. J. Dionne

G. E. Driver

B. H. Duane

M. D. Erickson

E. A. Eschbach

T. W. Evans

H. P. Foote

L. H. Gerhardstein

D. W. Hartmann

R. E. Heineman

P. L. Hofmann

R. T. Jaske

H. G. Johnson

W. F. Lenzke

C. W. Lindenmeier

W. W. Little

J. D. Lodge

W. B. McDonald

W. R. McSpadden

W. L. Nicholson

C. A. Oster

R. E. Peterson

R. L. Reynold

R. L. Richardson

J. T. Russe11

R. J. Squires

G. R. Taylor

N. P. Wilburn

D. C. Worlton

G. A. Worth 


$$
\text { Dist } r-5
$$

BNWL -940

No. of

Copies

Batte11e-Northwest (contd)

W. R. Young

FFTF Files

Technical Information Files

Technical Publications

(2) 


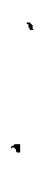

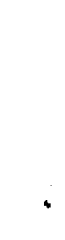

, 